\title{
Chapter
}

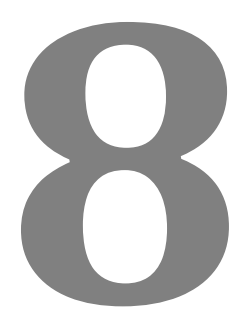

\section{THERMAL ANALYSIS AND CALORIMETRIC METHODS APPLIED TO PHARMACEUTICAL SOLID FORMS}

\author{
Danièle Giron
}

\section{Contents}

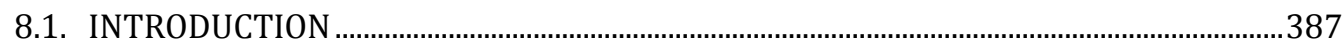

8.2. BASIC PRINCIPLES OF THERMAL METHODS AND THEIR IMPORTANCE IN

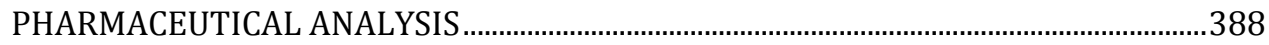

8.2.1. Thermal analysis methods .................................................................................... 388

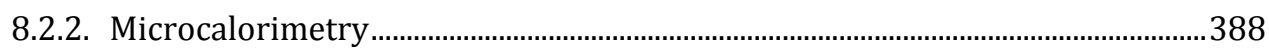

8.2.3. Overview of applications..............................................................................................388

8.3. FACTORS TO BE CONSIDERED IN THE INSTRUMENTATION .........................................391

8.3.1. Heat flux differential scanning calorimetry (DSC) and power compensation DSC .....................................................................................................

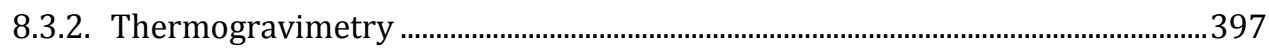

8.4. WHAT ARE THE AREAS OF APPLICATION FOR THE STUDY OF SOLID FORMS?......400

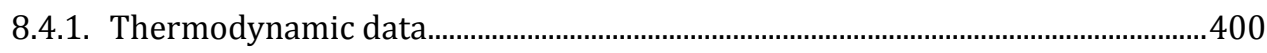


8.4.1.1. Two polymorphic solid phases................................................................... 400

8.4.1.2. The phase diagrams of salts, solvates and hydrates .............................. 404

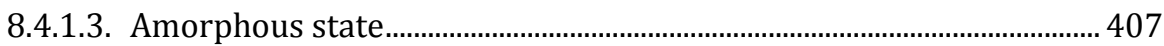

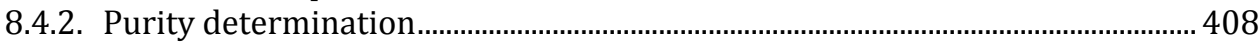

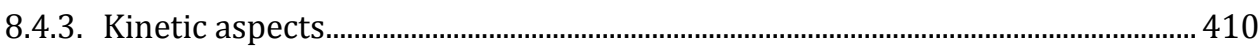

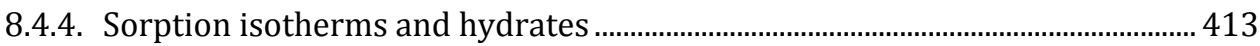

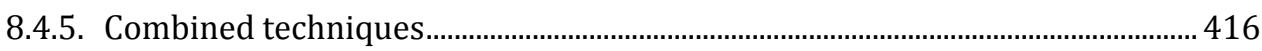

8.4.5.1. Combination of DSC and XRD ............................................................... 416

8.4.5.2. Thermogravimetry-mass spectrometry (TG-MS) and thermogravimetry-infrared spectroscopy (TG-IR) ...............................4 416

8.4.6. Isothermal microcalorimetry and solution calorimetry........................................ 421

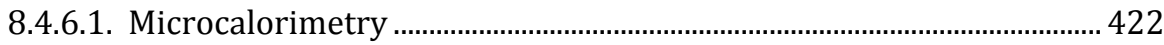

8.4.6.2. Solution calorimetry............................................................................... 424

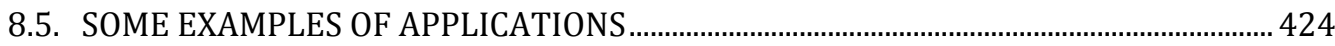

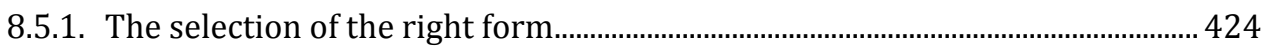

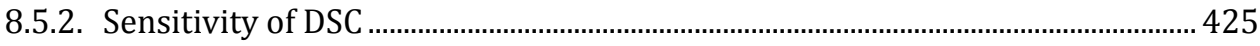

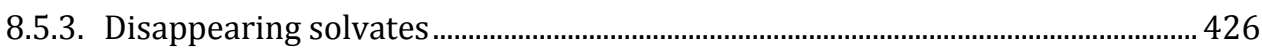

8.5.4. Selection of the best form considering the pharmaceutical environment ..... 426

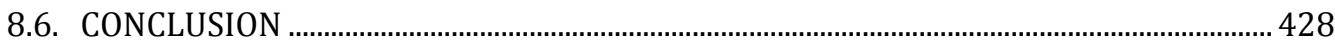

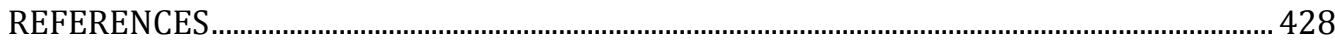




\subsection{INTRODUCTION}

Thermal analysis techniques, in which a physical property is monitored as function of temperature or time while the analyte is heated or cooled under controlled conditions, are fundamental techniques for the characterisation of drug substances and products. They are fundamental as processing or aging conditions may be simulated, and because the methods give access to thermodynamic data. Due to the different information conveyed, thermal analysis methods are complementary to other analytical techniques, such as spectroscopy, chromatography, melting point determination, loss on drying, assays for identification, purity and quantitation. Thermal analysis techniques are basic methods in the field of solid state analysis, in physical and chemical characterisation of pure substances, as well as for mixtures. They find the best application in pre-formulation, processing and control of the drug product. The introduction of sophisticated, automated, robust and sensitive instruments considerably increased the advantages of these methods. New horizons have been opened with the availability of combined techniques and microcalorimetry, an emerging technique which is now used routinely.

Since changes in temperature and moisture might induce the changes in the solid state, processing and storage may have a considerable effect on activity, toxicity and stability of compounds. The pharmaceutical industry is faced with the new challenges of quicker development and higher performance, in terms of technology, reliability and up-scale in the international current Good Manufacturing Practise (cGMP) environment. Current requirements set by the International Conference of Harmonisation (ICH) for the characterisation and the quantitation of polymorphism in new entities [1], re-enforce the position of thermal analysis and microcalorimetric techniques, which can deliver the correct information concerning the thermodynamic relationships between phases, for the proper selection of salt and crystal forms. The amorphous state is better understood and determinable. Differential scanning calorimetry (DSC) purity analysis is a fast, absolute, orthogonal purity technique for organic compounds. Microcalorimetry, DSC and thermogravimetry (TG) are advantageous in the process of design of drug products. 


\subsection{BASIC PRINCIPLES OF THERMAL METHODS AND THEIR IMPORTANCE IN PHARMACEUTICAL ANALYSIS}

\subsubsection{Thermal analysis methods}

When a material is heated or cooled, there is a change in its structure or composition. These transformations are connected with a heat exchange. The first application of thermal analysis was presented by Le Chatelier in 1887 [2]. In differential thermal analysis (DTA), the temperature induced in the sample is measured. DSC, which determines the heat flow into and out of the sample, as well as the temperature of the thermal phenomenon during a controlled change of temperature, is the basic thermal technique used for solid forms. Thermal analysis techniques also cover all other techniques in which a physical property is monitored as a function of temperature or time, while the sample is heated or cooled under controlled conditions. For the solid state, the phase diagram rules for single compounds, as well as for mixtures of several components, have to be considered.

The most common methods used in solid state characterisation are: DSC and TG, and they are often combined with mass spectrometry, X-ray diffraction (XRD), IR, Raman spectroscopy and microscopy. Books and reviews dealing with the principles, instrumentation and applications are given in references [3-10]. Specific applications of thermal analysis and calorimetric methods for pharmaceutical polymorphism are given in references [11-19].

\subsubsection{Microcalorimetry}

A calorimeter measures the heat flow into or out of a sample, whereas a differential calorimeter measures the heat of a sample relative to a reference. A differential scanning calorimeter combines these two methods, and additionally, heats the sample with a linear temperature ramp.

Microcalorimetry in isothermal mode is a growing technique, complementary to DSC for the characterisation of pharmaceuticals [20]. Larger sample volume and higher sensitivity mean that phenomena of very low energy, immeasurable by DSC, may be studied. The output of the instrument is measured by the rate of heat change $(\mathrm{d} q / \mathrm{d} t)$, as a function of time, with a sensitivity better than $0.1 \mu \mathrm{W}$. Microcalorimetry can be applied to isolated systems in specific atmospheres, or for batch mode, where reactants are mixed in the calorimeter. The most useful application currently, thanks to high throughput microcalorimeters [21], is the routine quantitation of undesirable amorphous content down to 0.1 - $0.3 \%$ [22-25].

Solution calorimetry can be used in adiabatic or isoperibol modes in microcalorimeters at constant temperature. This method is used for polymorphic interpretation and for quantitation [12].

\subsubsection{Overview of applications}

The processing of the drug substances and drug products involves solvent(s), temperature and pressure changes, as well as mechanical stress and, as a result, 
different solid phases may coexist in the drug product. Organic substances show supersaturation behaviour and unstable solid phases which should not exist at a defined temperature, pressure and humidity, but may behave like stable forms. These solid metastable phases, obtained outside of their domains of stability, will convert to their thermodynamically stable forms at given temperatures, pressures and relative humidities, in response to changes in environmental conditions, processing, or over time. These conversions, driven by thermodynamics, are governed by kinetics and are influenced by impurities, particle size, crystal defects and presence of seeds.

The market withdrawal of Ritonavir in 1998, one year after its launch, was caused by it having a rate of dissolution that was far too slow, due to an insoluble stable polymorph not found during development [26]. The current focus of research in the solid-state area is to understand the origin of polymorphism at the molecular level, and to predict and prepare the most stable form at the start of development. The selection of a metastable form should result from targeted choice, rather than from chance. The advantage of thermal and microcalorimetric techniques is that their sensitivity allows a sample size of considerably less than $1 \mathrm{mg}$. Table 8.1 summaries the analysis methods detailed, including coupled and combined techniques.

Table 8.1. Main thermal analysis techniques and calorimetry

\begin{tabular}{|c|c|c|}
\hline Technique & Measurements & Thermal events \\
\hline $\begin{array}{c}\text { Differential Scanning } \\
\text { Calorimetry (DSC) } \\
\text { Derivative DSC (DDSC) } \\
\text { Micro-DSC } \\
\text { Hyper-DSC }\end{array}$ & $\begin{array}{l}\text { Heat flow into and out } \\
\text { of the sample as a } \\
\text { function of } \\
\text { temperature/time }\end{array}$ & $\begin{array}{c}\text { Every thermal event associated with energy change } \\
\text { during heating or cooling } \\
\text { melting, boiling, sublimation and crystallisation } \\
\text { glass transition } \\
\text { polymorphic phase transition } \\
\text { desolvation, dehydration and isomerisation } \\
\text { complex phase transition } \\
\text { thermal degradation } \\
\text { mixtures; phase diagrams } \\
\text { purity determination } \\
\text { oxidation, catalysis } \\
\text { chemical reaction } \\
\text { kinetic analysis } \\
\text { coupling with TG, microscopy or X-ray }\end{array}$ \\
\hline Modulated DSC (MDSC) & $\begin{array}{l}\text { Total heat flow, } \\
\text { irreversible and } \\
\text { reversible heat flow }\end{array}$ & $\begin{array}{c}\text { every transition } \\
\text { distinction between overlapping thermal events } \\
\text { study of relaxation of glass transition }\end{array}$ \\
\hline $\begin{array}{l}\text { Thermogravimetry (TG) } \\
\text { Derivative } \\
\text { thermogravimetry (DTG) }\end{array}$ & $\begin{array}{l}\text { Change in sample mass } \\
\text { as a function of } \\
\text { temperature and/or } \\
\text { time }\end{array}$ & $\begin{array}{c}\text { Every change of mass } \\
\text { desolvation, dehydration } \\
\text { sorption-desorption isotherms } \\
\text { degradation } \\
\text { compositional analysis } \\
\text { chemical reaction } \\
\text { kinetic analysis } \\
\text { drying optimisation } \\
\text { coupling with DSC, GC, MS, IR, Raman }\end{array}$ \\
\hline
\end{tabular}




\begin{tabular}{|c|c|c|}
\hline Technique & Measurements & Thermal events \\
\hline $\begin{array}{l}\text { Thermomechanical } \\
\text { Analysis (TMA), } \\
\text { Thermodilatometry }\end{array}$ & $\begin{array}{l}\text { Dimensional changes } \\
\text { during compression, } \\
\text { penetration, tension, } \\
\text { flexure or torsion } \\
\text { versus temperature }\end{array}$ & $\begin{array}{c}\text { Mechanical properties, dimensions } \\
\text { expansion, dilatation } \\
\text { glass transition } \\
\text { gelification, swelling }\end{array}$ \\
\hline $\begin{array}{l}\text { Dynamic mechanical } \\
\text { analysis (DMA) }\end{array}$ & $\begin{array}{l}\text { Dimensions versus } \\
\text { frequency and } \\
\text { temperature }\end{array}$ & $\begin{array}{l}\text { Young modulus } \\
\text { polymer analysis }\end{array}$ \\
\hline $\begin{array}{l}\text { Thermally Stimulated } \\
\text { Current (TSC) } \\
\text { Dielectric Thermal } \\
\text { Analysis (DETA) } \\
\end{array}$ & $\begin{array}{c}\text { Depolarisation current } \\
\text { curve versus } \\
\text { temperature } \\
\text { Dielectric constant } \\
\end{array}$ & $\begin{array}{l}\text { relaxation alpha and beta of glasses } \\
\text { quantification of amorphous }\end{array}$ \\
\hline $\begin{array}{l}\text { Thermal Conductivity } \\
\text { (TC) }\end{array}$ & Thermal conductivity & $\begin{array}{l}\text { thermal conductivity, thermal diffusivity } \\
\text { on line analysis of processes }\end{array}$ \\
\hline Thermomicroscopy & $\begin{array}{c}\text { Microscopical } \\
\text { observation under } \\
\text { different modes of light } \\
\text { illumination during } \\
\text { heating or cooling }\end{array}$ & $\begin{array}{c}\text { melting, crystallisation, evaporation.. } \\
\text { eutectic formation } \\
\text { solubility studies } \\
\text { crystallinity using polarised light } \\
\text { morphological studies }\end{array}$ \\
\hline TG-MS, TG-Raman, TG-IR & $\begin{array}{l}\text { Coupled spectroscopic } \\
\text { analysis with TG }\end{array}$ & $\begin{array}{l}\text { analysis of volatiles } \\
\text { investigation of drying processes } \\
\text { investigation of solvates, hydrates } \\
\text { interpretation of thermal events }\end{array}$ \\
\hline $\begin{array}{l}\text { Evolved gas analysis } \\
\text { (EGA) }\end{array}$ & $\begin{array}{l}\text { TG coupled with GC } \\
\text { and possibly MS, IR }\end{array}$ & $\begin{array}{l}\text { Identification and quantification of volatile } \\
\text { components }\end{array}$ \\
\hline $\begin{array}{l}\text { Combined spectroscopic } \\
\text { methods }\end{array}$ & $\begin{array}{l}\text { Programmed heating } \\
\text { cell with spectroscopic } \\
\text { analysis (IR, Raman, } \\
\text { NMR, Terahertz)) }\end{array}$ & $\begin{array}{l}\text { spectroscopic data of phases obtained in situ during } \\
\text { combined with Thermomicroscopy } \\
\text { interpretation of thermal events }\end{array}$ \\
\hline $\begin{array}{l}\text { Temperature resolved } \\
\text { XPRD or } \\
\text { coupled DSC/XRD }\end{array}$ & $\begin{array}{l}\text { X-ray powder } \\
\text { diffraction versus } \\
\text { temperature }\end{array}$ & $\begin{array}{l}\text { interpretation of thermal events } \\
\text { identification of phases in situ } \\
\text { XPRD of unstable forms } \\
\text { combined with modelling }\end{array}$ \\
\hline Microcalorimetry & $\begin{array}{l}\text { Heat flux out of the } \\
\text { sample in Isothermal } \\
\text { mode }\end{array}$ & $\begin{array}{c}\text { heat of solution } \\
\text { heat of transformation, heat of reaction } \\
\text { quantification of amorphous } \\
\text { stability prediction } \\
\text { kinetic } \\
\end{array}$ \\
\hline Nano-DSC & $\begin{array}{l}\text { Heat flux out of the } \\
\text { sample }\end{array}$ & $\begin{array}{l}\text { Specially designed for life science, folding of proteins, } \\
\text { siRNA used for quality control in biological science }\end{array}$ \\
\hline $\begin{array}{c}\text { Calorimetry } \\
\text { Accelerated calorimetry } \\
\text { Reaction calorimetry }\end{array}$ & Heat measurement & $\begin{array}{c}\text { safety } \\
\text { simulation of processes } \\
\text { simulation reactors }\end{array}$ \\
\hline Titration calorimetry & $\begin{array}{l}\text { Heat measurement } \\
\text { during addition of } \\
\text { reactant }\end{array}$ & $\begin{array}{l}\text { binding constant } \\
\text { study of molecular binding of proteins, native cells } \\
\text { drug-cells interactions }\end{array}$ \\
\hline Micro-thermal analysis & $\begin{array}{l}\text { Heat flux and atomic } \\
\text { force microscopy }\end{array}$ & $\begin{array}{c}\text { Topography, with conductivity and thermal diffusivity } \\
\text { interfaces studies }\end{array}$ \\
\hline
\end{tabular}




\subsection{FACTORS TO BE CONSIDERED IN THE INSTRUMENTATION}

Modern instruments used for thermal analysis usually consist of four parts:

- the sample and sample holder,

- sensors to detect and measure a property of the sample, as well as the temperature,

- a system within the instrument that allows the experimental parameters to be controlled,

- a computer to control data collection and processing.

\subsubsection{Heat flux differential scanning calorimetry (DSC) and power compensation DSC}

DSC measures the temperature and the heat flow associated with transitions in materials, as a function of time and temperature, in a controlled atmosphere and relative to a reference. These measurements provide quantitative and qualitative information about physical and chemical changes that involve endothermic or exothermic processes, or changes in heat capacity.

The principle of DSC is as follows: two ovens are heated in a linear manner. One oven contains the sample in a pan; the other contains an empty pan as a balance, termed a reference pan. If nothing occurs to the sample then the sample pan and reference pan are at the same temperature during heating. If a change, such as melting occurs in the sample, then energy is used by the sample and the temperature remains constant in the sample pan during melting. Therefore, a difference of temperature occurs between the sample pan and reference pan.

Two methods of measurement are used by manufacturers. The first method is termed "heat flux DSC", in which the instrument measures the temperature difference (DTA). Through calibration, this temperature difference is transformed into heat flow $(\mathrm{d} q / \mathrm{d} t)$. The instrument contains a furnace, which is a block for both sample and reference cells. The sample holder contains the sample pan, and the reference pan is connected by a low resistance heat flow path; thermocouples are used for determining the temperature difference between sample and reference.

In the second method, which is termed "power compensation DSC", two individual heaters are used in order to monitor the individual heating rates of the two individual ovens. A system controls the temperature difference between sample and reference. If any difference is detected, the specific heater will be corrected so that the temperature is kept the same in both pans. That is, when an endothermic or exothermic process occurs, the instrument delivers the compensation energy which must be given in order to maintain equal temperatures in both pans.

In the first method (heat flux DSC), temperature is primarily measured, in the second case (power compensation DSC), energy is primarily measured. Despite their different modes of operation, both instruments deliver the same information: heat flow as a function of temperature (or time). 
For first order transitions, such as melting, crystallisation, sublimation, boiling etc., integration of the curve gives the energy involved in the transition. Melting, boiling, sublimation and desolvation are endothermic, which means they need energy. Crystallisation is exothermic, which means that it supplies energy. Solidsolid phase transition and decomposition may be endothermic or exothermic. For second order transitions, the signal gives the change in the specific heat; for example, in the glass transitions of amorphous materials. Manufacturers represent the heat flow differently: endotherms have the positive values in power compensation DSC, and negative values for heat flux DSC. Figure 8.1 shows typical transitions for a single compound: with a power compensation DSC with an endotherm rising, or for heat flux DSC with an endotherm falling. Both representations are accepted if the signs for endotherm or exotherm are given on the curves. Generally the temperature is plotted on the $x$ abscissa (usual given in $\left.{ }^{\circ} \mathrm{C}\right)$ and the heat flow $(\mathrm{d} Q / \mathrm{d} t, \mathrm{~d} q / \mathrm{d} t$ or $\mathrm{d} H / \mathrm{d} t)$ is plotted on the $y$ ordinate in $\mathrm{J} \mathrm{s}^{-1}$. Most recent curves are given in mWatts $(\mathrm{mW})$, which is equivalent, and in this chapter both expressions are used. Melting, crystallisation and phase transitions are first order transitions. The intersection between the baseline and the slope of the peak is the extrapolated temperature onset of the transition $\left(T_{\mathrm{e}}\right)$. The corresponding energy is the area under the peak. The peak temperature $\left(T_{\mathrm{m}}\right)$ is very dependent on instrument and measurement parameters. The glass point, which is a second order transition, is determined as an inflexion point.

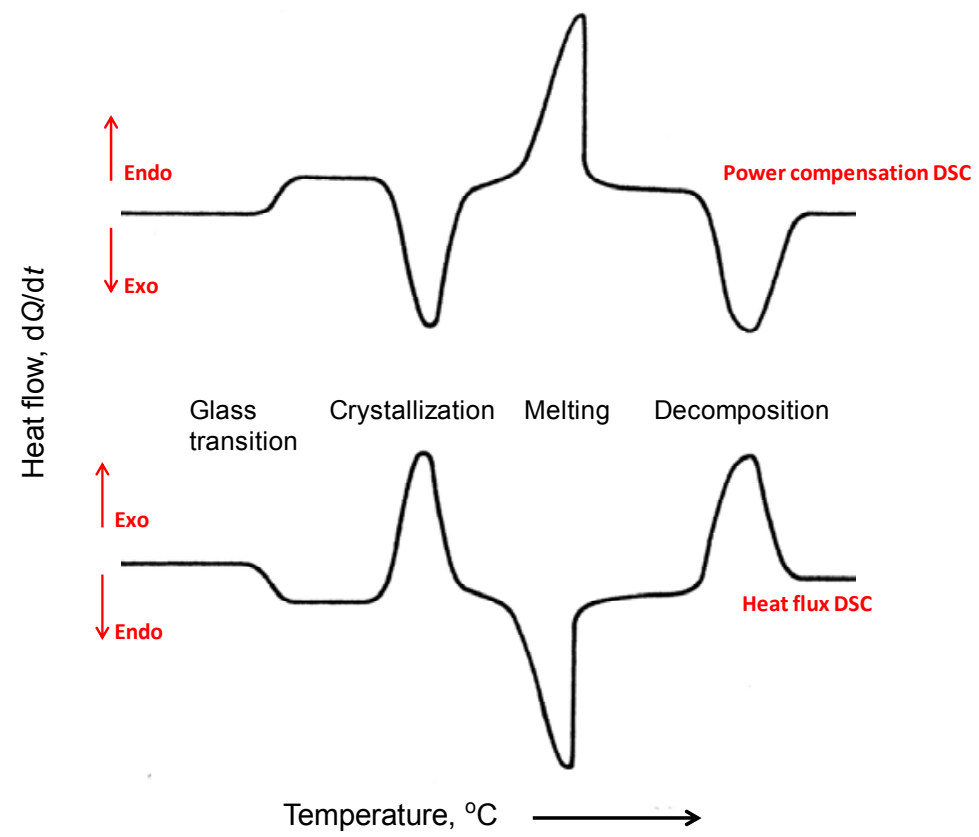

Figure 8.1. Examples of a power compensation and heat flux DSC curves for a single compound 
Modern instruments permit the heating, cooling and isotherm curves between sub-ambient temperatures, with use of a cooling device, and higher temperatures in the range of $1200-1500{ }^{\circ} \mathrm{C}$. Curves made using different instruments cannot be compared to one another; corrections must be calculated according to each instrument. Great care must be given to the temperature, with the temperature plotted on the abscissa being the programmed temperature, not the real temperature of the sample. The actual temperature depends on the thermal resistance and heating rate of the instrument, which is called the "thermal lag" of the system. The correlation between apparent melting point and heating rate depends on the manufacturer. Generally, pure indium (>99.9999 \%) is used with each series of measurements. Modern instruments, with data handling, enable the true temperature of each point of the DSC curve to be calculated.

Figure 8.2 exemplifies the effect of the heating rate on the DSC curves. An example of the DSC curves of indium using different heating rates on a DSC-2 Perkin-Elmer instrument is given in Figure 8.2a. Since energy is the integration of the signal as a function of the time, the DSC curves are not identical at every heating rate. The "thermal lag" is instrument specific. Since the melting temperature of indium is $156.6^{\circ} \mathrm{C}$, the extrapolated onset has to be corrected for each heating rate. Figure $8.2 \mathrm{~b}$ shows the plot of the extrapolated onset of the curves for indium versus heating rate at $1.25,2.0,5.0,10.0$ and $20{ }^{\circ} \mathrm{C} \mathrm{min}-1$. This effect has to be taken into consideration when comparing curves obtained using different heating rates, and especially if measured with different instruments.
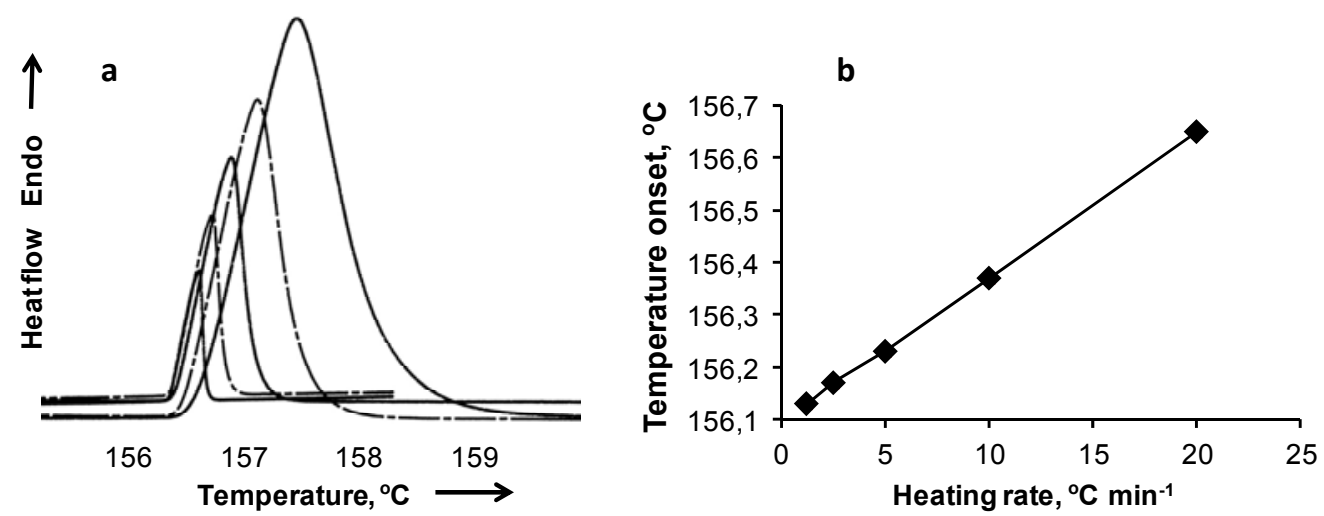

Figure 8.2. Effect of heating rate on the melting point of indium.

(a) DSC curves at $1.25,2.0,5.0,10.0$ and $20.0{ }^{\circ} \mathrm{C} \mathrm{min}^{-1}$;

(b) corresponding linear relationship between melting point and heating rate

Figure 8.3 shows the influence of heating rate on the resolution of polymorphs of temazepam. The best resolution is obtained with a low heating rate. Figure 8.4 exemplifies the influence of the sample mass on the resolution for the same compound. The heating rate (sensitivity of the instrument), and the sample mass have to be chosen carefully to detect thermal effects which are very close to one another. 


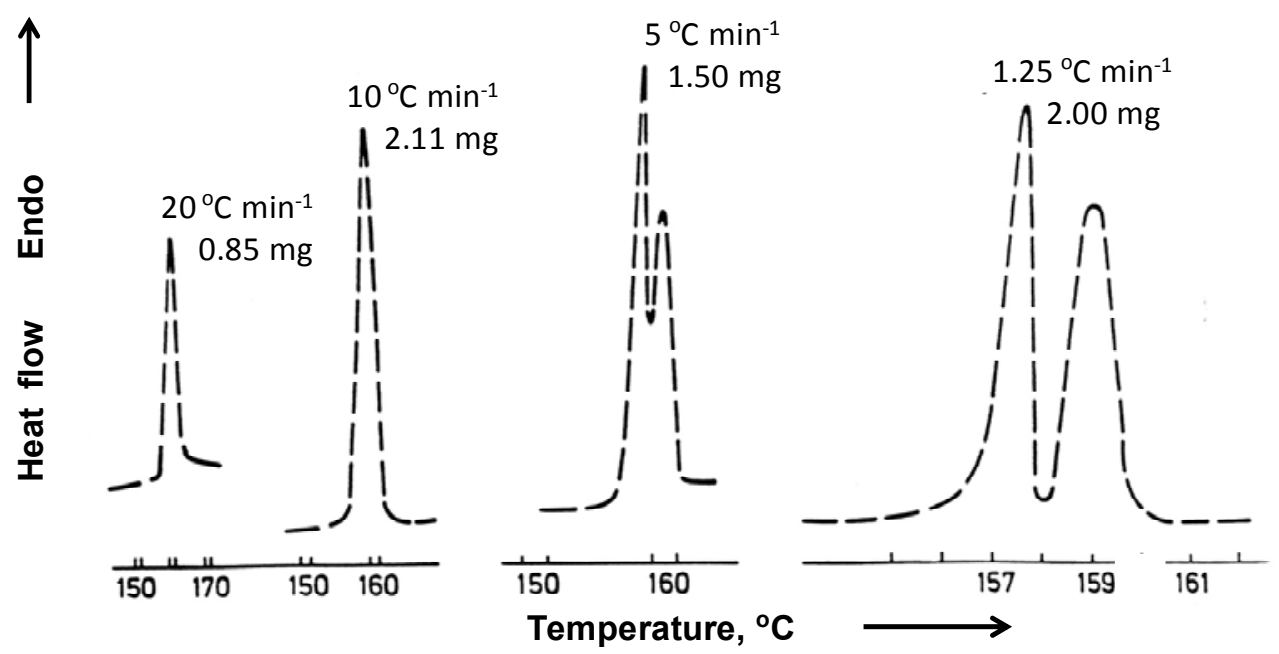

Figure 8.3. DSC curves showing the effect of heating rate on the resolution of polymorphs of temazepam
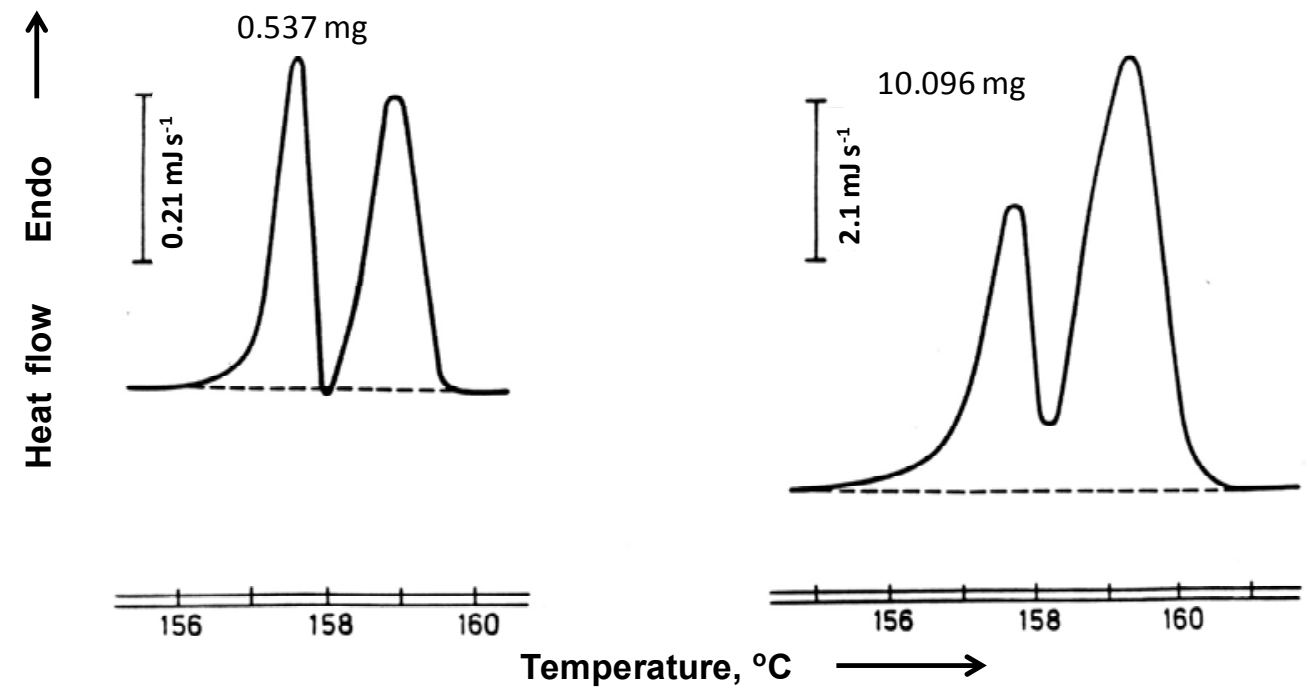

Figure 8.4. DSC curves showing the effect of sample mass on the resolution of polymorphs of temazepam. Heating rate $1.25^{\circ} \mathrm{C} \mathrm{min}-1$

Figure 8.5 deals with the measurement of the glass transition with and without thermal effect. The thermal effect appearing as a maximum on DSC curve depends on the thermal history of the sample, and is commonly used in the study of amorphous materials and polymers. At high heating rates the signal is higher because, for the glass transition the change in $c_{p}$ is $\mathrm{d} q / \mathrm{d} t$ or $\mathrm{d} H / \mathrm{d} t$, and is easier to measure. 

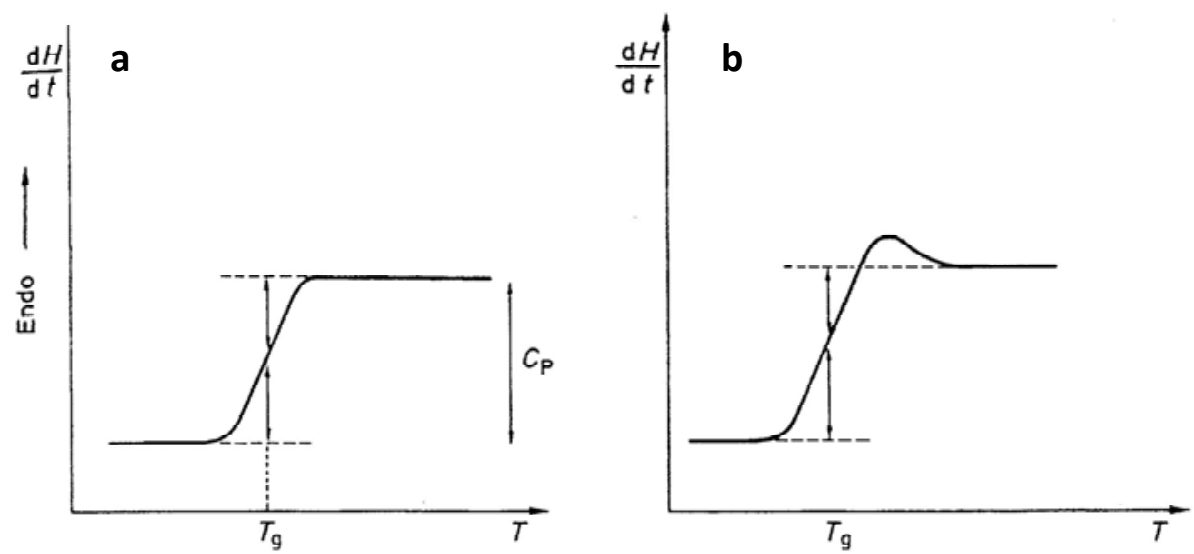

Figure 8.5. DSC curves for the glass transition (a) without thermal effect and (b) with thermal effect

Great efforts have been made in recent years to validate different instruments, not only in comparing principles and results, but also in determining heating and cooling rates, particle size, weight, resolution, atmosphere and type of pans. The type and the size of pans is of great importance for comparing results; types of pan may include open pan, crimped pan, sealed pan or pin hole. The same type of pans must be used for both sample and reference. If pans are hermetically closed then the solvent cannot escape, and the curves are not the same as for pans with a pin hole. Figure 8.6 exemplifies the problem for a monohydrate. In a sealed pan, the DSC melting peak of the monohydrate is observed. Whereas, if a pin hole is made in the cover of the pan, water can escape and the transition into the anhydrous form is observed as endothermic/exothermic phenomenon before the melting of the anhydrous form occurs. Unlike the curves for monohydrate, the anhydrous form is not affected by the type of the pan.

The use of flowing purge gas (nitrogen or argon) is required as the waste products from sublimation or decomposition have to be removed. Due to the lubricant used in the manufacture of aluminium pans, these pans must be preheated in order to avoid artefacts. The homogeneity of the sample, the sample preparation, any contaminations, the time between the manufacture of the sample and its measurement, the sample mass and thermal lag are the main source of errors. In pharmaceutical development, instruments must be calibrated and routinely checked. It should be emphasised that melting points of polymorphs may differ by less than $1{ }^{\circ} \mathrm{C}$, and that differences in melting energy are often less than $5 \%$. Therefore, all variables of an automated device have to be controlled.

Table 8.2 deals with examples of standards, including IUPAC and WHO standards, proposed for temperature calibration. The standards must be of certified purity. For heat calibration, the melting energies of certified substances with melting points between $60^{\circ} \mathrm{C}$ and $230^{\circ} \mathrm{C}$ are proposed in Table 8.2. 


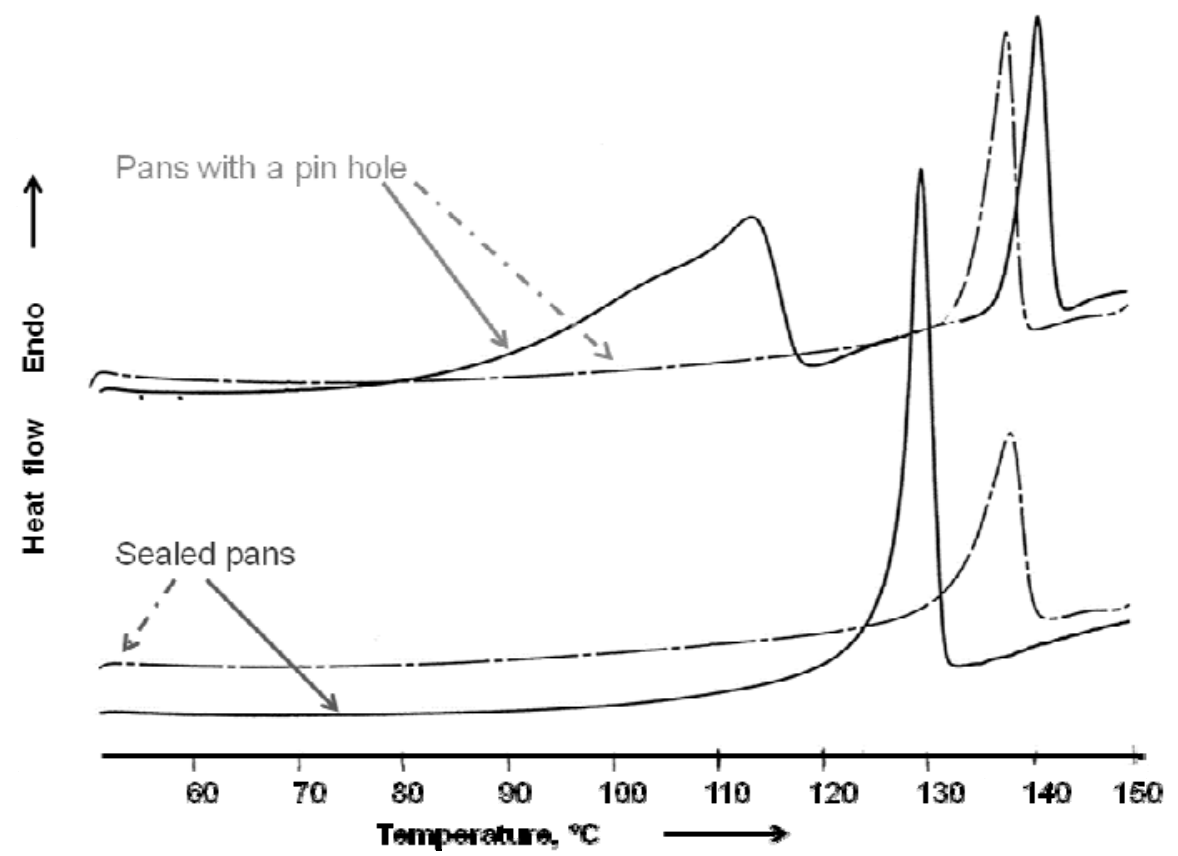

Figure 8.6. Effect of the type of pan on DSC curves for a monohydrate (-) and for an anhydrous form - - -). With the sealed pan, one may measure the melting of the hydrate. With pin hole, water escapes and a recrystallisation into the anhydrous form is observed

Table 8.2. Certified substances for the calibration of DSC instruments

\begin{tabular}{cccc}
\hline Certified substance & $\begin{array}{c}\text { Melting } \\
\text { temperature, }{ }^{\circ} \mathbf{C}\end{array}$ & Standard substance & Melting energy, J g-1 \\
\hline Iodobenzene & -31.3 & Naphthalene & 148.6 \\
\hline $\mathrm{H}_{2} \mathrm{O}$ & 0.0 & Benzil & 112.0 \\
\hline 4-nitrotoluene & 51.5 & Benzoic acid & 147.2 \\
\hline Biphenyl & 69.3 & Biphenyl & 120.4 \\
\hline Naphthalene & 80.2 & Diphenylacetic acid & 146.9 \\
\hline Benzil & 94.7 & Indium & 28.7 \\
\hline Acetanilide & 114.0 & Tin & \\
\hline Benzoic acid & 122.1 & & \\
\hline Diphenylacetic acid & 146.5 & & \\
\hline Indium & 156.6 & & \\
\hline Anisic acid & 183.1 & & \\
\hline 2-chloro-anthraquinone & 210.0 & & \\
\hline Tin & 231.9 & & \\
\hline Antraquinone & 284.5 & & \\
\hline Lead & 327.5 & & \\
\hline Zinc & 418.9 & \\
\hline
\end{tabular}


In modulated DSC (MDSC), the normally linear heating ramp is overlaid with a sinusoidal function, or an oscillating function defined by a frequency and an amplitude, to produce a sine wave shaped temperature versus time function. Using Fourier mathematics, the DSC signal is then split into two components: one reflecting non-reversible events (kinetic), and the other reversible events. This method is generally not applied in the characterisation of solid pharmaceutical forms. For details on this application, see [3-8].

\subsubsection{Thermogravimetry}

In thermogravimetry (TG), the change in sample mass is determined as a function of temperature and/or time. The instrument used is a thermobalance that allows the continuous weighing of a sample as a function of time. The sample holder and a reference holder are bonded to each side of a microbalance, in a vertical or horizontal design. The sample holder is situated in a furnace, without direct contact with the sample, the temperature of which is controlled by a temperature programmer. The balance portion is maintained at a constant temperature and the instrument is able to record the loss or gain in mass of the sample as a function of temperature and time $[m=f(T)]$. Frequently, the mass change is given as percentage of the sample. Most instruments also record the derivative of the mass change $[\mathrm{d} m / \mathrm{d} t=\mathrm{f}(T)]$.

The derivative TG (DTG) allows a better distinction of overlapping steps, and the determination of the temperature at which the rate of mass change is maximal or minimal. The area under the DTG curve is proportional to this mass change, and the height of the DTG peak at any temperature gives the rate of mass change. DSC and DTG performed on hydrates show the same outcome.

Balance is adjusted with certified mass at ambient temperature and it is recommended to check the mass at temperatures of use. Therefore, the author proposes three standards: calcium oxalate dihydrate (water content $12.3 \%$ ) (used for TG in European Pharmacopoeia), disodium tartrate dihydrate (water content $15.7 \%$ ) (used as standard for Karl Fischer analysis) and copper sulphate pentahydrate (water content $36.1 \%$ ). Figure 8.7 a shows such calibration curves at $20^{\circ} \mathrm{C} \mathrm{min}-1$ heating rate. The dehydrations cover a temperature range of 50 to $270{ }^{\circ} \mathrm{C}$. In this figure we plot for comparison the common excipient lactose monohydrate.

For temperature calibration, the standards recommended by ICTA are ferromagnetic standards exhibiting loss of ferromagnetism at their Curie point temperature within a magnetic field: Nickel $\left(354^{\circ} \mathrm{C}\right)$, Permanorm $3\left(266^{\circ} \mathrm{C}\right)$, Numetal $\left(386^{\circ} \mathrm{C}\right)$, Permanorm $5\left(459^{\circ} \mathrm{C}\right)$ and Trafoperm $\left(754^{\circ} \mathrm{C}\right)$. A thermobalance with horizontal plates is proposed by manufacturers as the melting of standards is easier for the user.

Tables 8.3a and 8.3b show calibrations of a thermobalance at different heating rates. In order to check the stability of the system, a baseline at the highest sensitivity has to be performed for all heating rates in the temperature range of analysis; the highest deviation will be observed at the highest heating rate. 

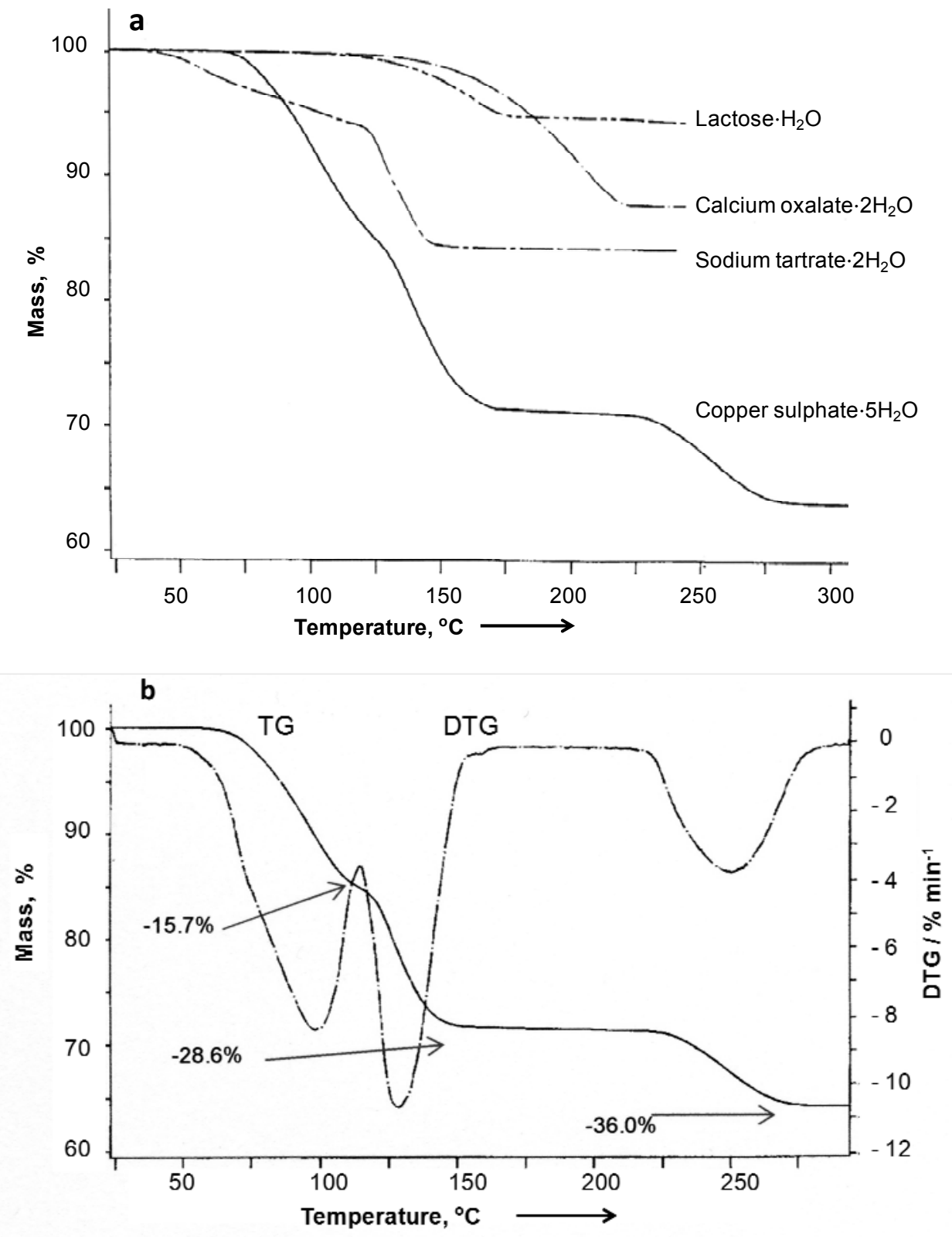

Figure 8.7. Thermogravimetry of standard organic substances at $20^{\circ} \mathrm{C} \mathrm{min}-1$.

(a) TG curves; (b) DTG compared to TG of copper(II) sulphate pentahydrate

Figure 8.7b shows the use of DTG for copper sulphate pentahydrate, at the same heating rate as given in Figure 8.7a. The DTG determines precisely the end of each step at rapid heating rates, which is an advantage when desolvation and decomposition overlap. Figure 8.8 exemplifies the effect of heating rate on TG 
curves of disodium maleate dihydrate. The results obtained at the $5{ }^{\circ} \mathrm{C} \mathrm{min}{ }^{-1}$ heating rate comply with the theoretical values of water content of the dihydrate $(18.45 \%)$.

Table 8.3a. Examples of the mass calibration of a thermobalance at different heating rates

\begin{tabular}{|c|c|c|c|c|}
\hline \multirow{2}{*}{ Substance } & \multirow{2}{*}{$\begin{array}{c}\text { Theoretical amount } \\
\text { of water, } \%\end{array}$} & \multicolumn{3}{|c|}{ Amount of water found, $\%$} \\
\hline & & $5^{\circ} \mathrm{C} \mathrm{min}^{-1}$ & $10^{\circ} \mathrm{C} \mathrm{min}^{-1}$ & $20^{\circ} \mathrm{C} \mathrm{min}^{-1}$ \\
\hline $\begin{array}{c}\text { Disodium tartrate } \\
\text { dihydrate }\end{array}$ & 15.65 & 15.73 & 15.60 & 15.73 \\
\hline $\begin{array}{l}\text { Calcium oxalate } \\
\text { monohydrate }\end{array}$ & 12.32 & 12.55 & 12.51 & 12.48 \\
\hline $\begin{array}{l}\text { Copper sulphate } \\
\text { pentahydrate }\end{array}$ & 36.07 & 36.08 & 36.03 & 36.04 \\
\hline
\end{tabular}

Table 8.3b. Examples of the temperature calibration of a thermobalance at different heating rates

\begin{tabular}{ccccc}
\hline \multirow{2}{*}{ Substance } & \multirow{2}{*}{$\begin{array}{c}\text { Theoretical } \\
\text { melting point, }\end{array}$} & \multicolumn{3}{c}{ Determined melting point, } \\
\cline { 3 - 5 } & ${ }^{\circ} \mathbf{C}$ \\
\hline 4-nitrotoluene & 51.50 & $\mathbf{5}^{\circ} \mathbf{C}$ min-1 & $\mathbf{1 0}^{\circ} \mathbf{C}$ in-1 & $\mathbf{2 0}^{\circ} \mathbf{C}$ min-1 \\
\hline Indium & 156.60 & 51.49 & 51.64 & 53.78 \\
\hline Tin & 231.93 & 157.62 & 157.38 & 157.74 \\
\hline
\end{tabular}

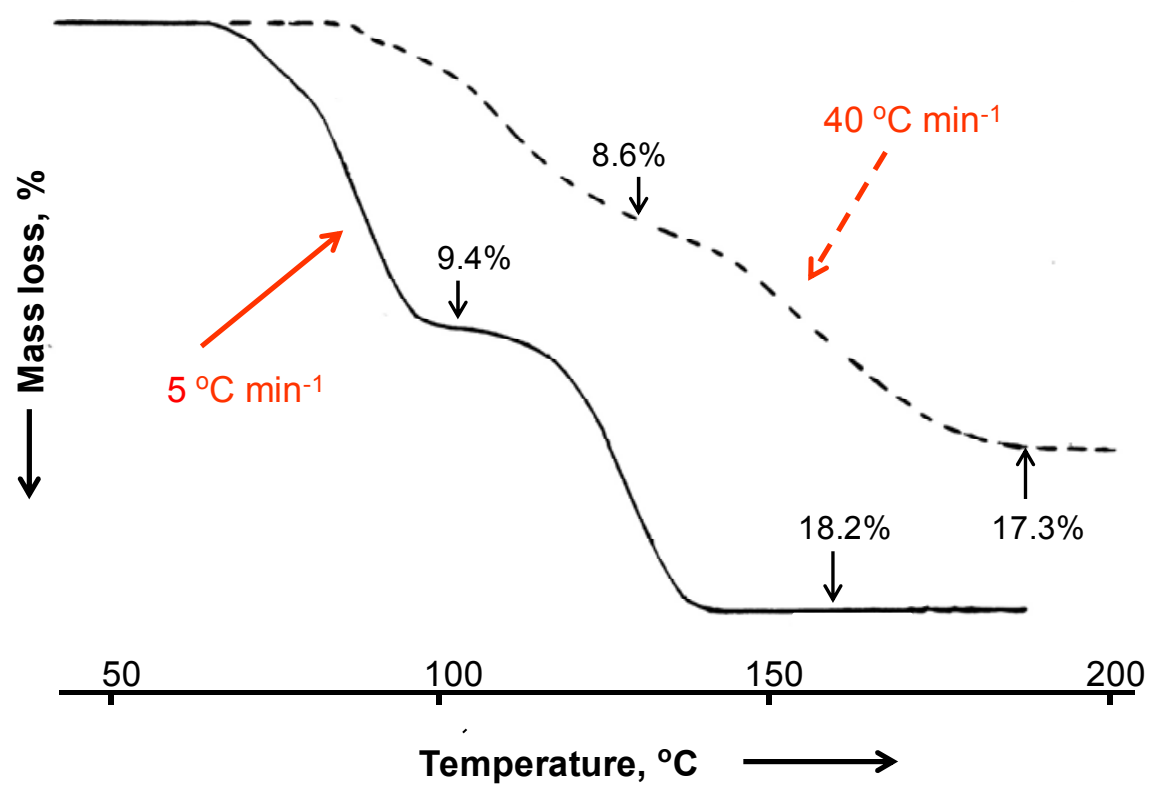

Figure 8.8. TG curves of disodiummaleate dihydrate at two different heating rates 


\subsection{WHAT ARE THE AREAS OF APPLICATION FOR THE STUDY OF SOLID FORMS?}

\subsubsection{Thermodynamic data}

Once solid form is obtained, several questions arise:

- Is the form a mixture of polymorphs?

- What is the chemical purity?

- What is the degree of crystallinity?

- Is the salt form pure?

- What are the thermodynamic windows:

o for true polymorphs?

o for solvated forms?

o for different hydrated forms?

o for the amorphous form?

These questions need to be answered quickly in order to measure correctly the physicochemical parameters of the isolated form.

Polymorphism is the ability of a substance to crystallise into different crystalline phases that have different arrangements, and/or conformations of the molecules, in the crystal lattice. These crystalline forms are called polymorphs, or crystalline modifications. Polymorphs have the same liquid or gaseous state, but they behave differently in the solid state. The amorphous state is characterised by solidification in a disordered or random manner, structurally similar to the liquid state. The expression pseudo-polymorphism applies to hydrates and solvates. Hydrates or solvates do not have the same chemical structure as the anhydrous forms, though polymorphism between hydrates or solvates does occur.

The relationships between different phases are governed by the Gibbs phase rule:

$$
V=C+2-\Psi
$$

where $V=$ variance, $C=$ number of components, $\Psi=$ number of phases.

\subsubsection{Two polymorphic solid phases}

In the case of two polymorphic solid phases, $C$ is equal to one. If two solid phases are present, and if both pressure and temperature vary, the variance is unity. If pressure is fixed, then variance is zero. Phase diagrams of pressure versus temperature illustrate the different equilibrium curves for polymorphism (Figure 8.9).

For each solid form, there is a solid-liquid equilibrium curve and a solid-vapour equilibrium curve. In the case of enantiotropy, there is an equilibrium curve (BF in Figure 8.9a), where both polymorphs are in equilibrium and undergo reversible transition at a specific temperature and at a fixed pressure. In the case of monotropy (Figure 8.9b), there is no thermodynamic transition between two phases, since only one solid form is thermodynamically stable. The dashed lines correspond to the metastable equilibrium curves which have to be taken into consideration. 


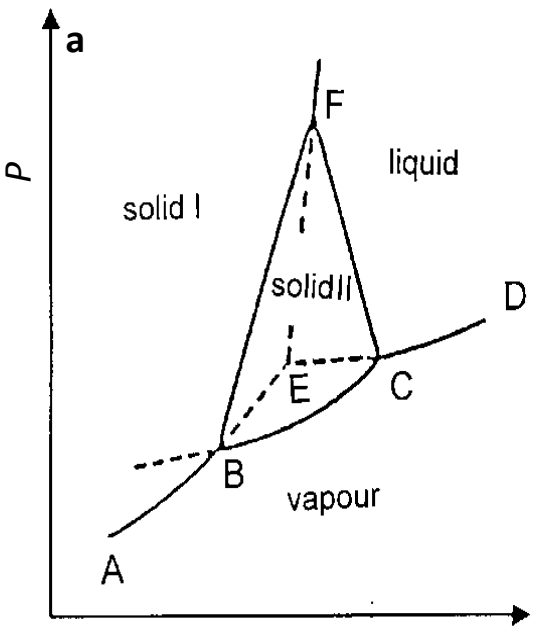

$T$

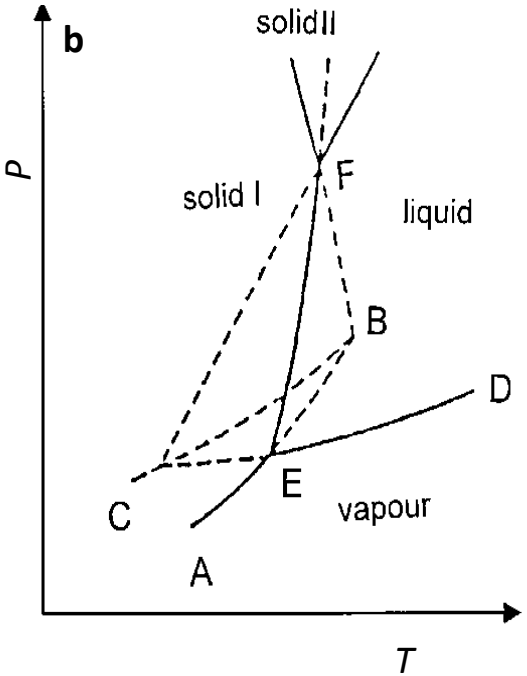

$T$

Figure 8.9. Phase diagrams $P, T$ for a single compound showing (a) enantiotropic and (b) monotropic polymorphism

The ability of a system to perform work, and to undergo a spontaneous change at constant pressure is measured by the Gibbs energy, $\Delta G . \Delta G$ has been defined in terms of enthalpy and entropy changes, $\Delta H$ and $\Delta S$, at temperature $T$ as:

$$
\Delta G=\Delta H-T \Delta S
$$

Gibbs energy $(G)$, enthalpy $(H)$ and entropy $(S)$ are state functions and the term $\Delta$ can be omitted.

$$
G=H-T S
$$

At 0 Kelvin, $G=H$. Since the entropy $S$ is always positive, $G$ decreases with increasing temperature. The energy diagram, $G$ versus temperature at a given pressure, reflects the transition observed between both solid phases, and between solid and liquid phases. If a transition between phases occurs then at this temperature both phases have the same Gibbs energy, $G$.

In general, the thermodynamic relationship between two polymorphic phases is represented by plotting Gibbs energy as a function of temperature for each form (Figure 8.10). If the two curves intersect below the melting point of each polymorph, a reversible transition occurs at the temperature $T_{\mathrm{t}}$ of the intersection. At temperatures below $T_{\mathrm{t}}$, polymorph A has the lower Gibbs energy and is therefore the thermodynamically stable form, while at temperatures above $T_{\mathrm{t}}$, polymorph B is stable. The transition point can be low, even below ambient temperature, or in other cases, very high (above $200{ }^{\circ} \mathrm{C}$ ). In the case of monotropy, there is no intersection of the Gibbs energy of both forms, and the higher melting form is always the thermodynamically stable form. 

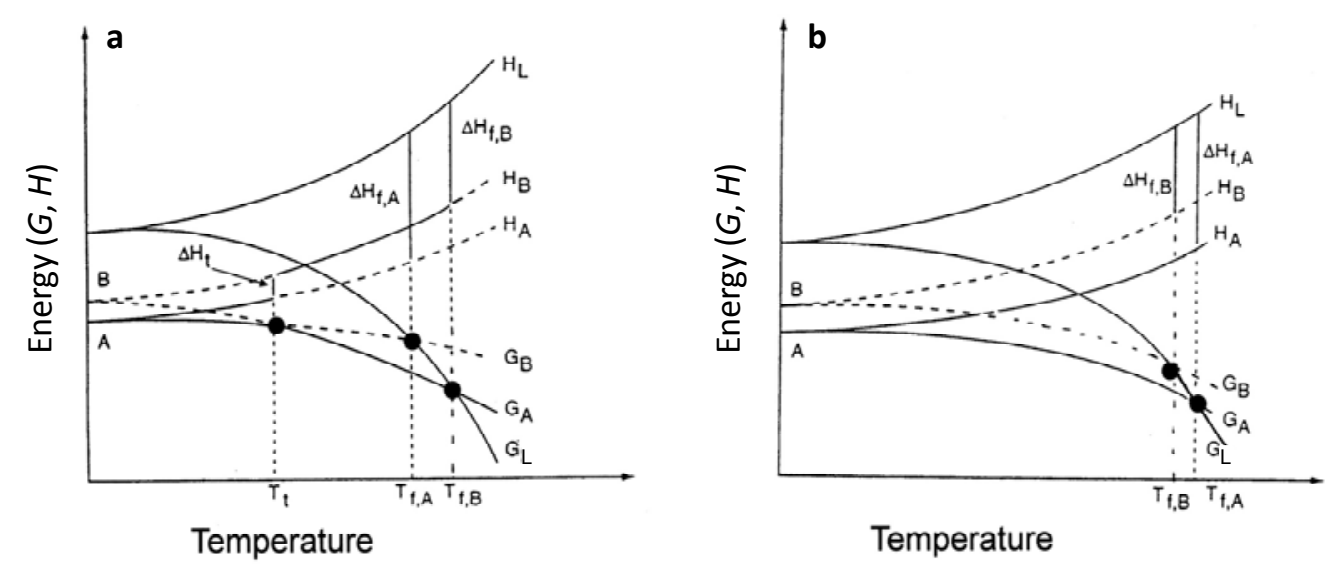

Figure 8.10. Energy diagrams depicting dependences of $H$ and $G$ vs. temperature for (a) enantiotropic and (b) monotropic compound

The relative position of the G-isobars $\left(\Delta G_{\mathrm{A} \rightarrow \mathrm{B}}\right)$ of different modifications can be determined by solubility experiments in a given solvent:

$$
\Delta G_{\mathrm{A} \rightarrow \mathrm{B}}=R T \ln \left(S_{\mathrm{A}} / S_{\mathrm{B}}\right)
$$

where $S_{\mathrm{A}}$ is the saturation solubility of the modification $\mathrm{A}$ and $S_{\mathrm{B}}$ is the saturation solubility of the modification B.

Each crystal form has its own heat capacity, which is a function of the enthalpy $H$ and the temperature. The heat capacity of solids at constant volume and constant pressure are about the same. The $H$ isobars of the two modifications are parallel and their distance is the transition enthalpy $\Delta H_{\mathrm{t}}$.

Burger [27-28], proposed to plot energy/temperature diagrams of the Gibbs energy $(G)$ and the enthalpy $(H)$, as functions of temperature. This proposal is the fundamental tool for the solution of complex polymorphic systems. As shown in Figures $8.10 \mathrm{a}$ and $8.10 \mathrm{~b}$, a notable difference between enantiotropy and monotropy is the melting enthalpy of the higher melting form. In the case of enantiotropy, the higher melting form has the lower melting enthalpy. In the case of monotropy, the higher melting form has the higher melting enthalpy.

DSC, which measures every heat flow change upon heating or cooling, is the most appropriate technique, since the method allows us to determine the melting points and the melting enthalpies, as well as the transition points and the corresponding energy. The influence of kinetics can be followed by using different heating rates and tempering in situ [12].

The relationship between melting enthalpies of two solid phases A and B, and the heat of transition is approximately:

$$
\Delta H_{\mathrm{t}}=\Delta H_{\mathrm{fA}}-\Delta H_{\mathrm{fB}}
$$


The temperature of transition between two enantiotrops can be calculated according to Equation 8.6 by neglecting the differences in specific heat.

$$
T_{\mathrm{t}}=T_{\mathrm{A}} T_{\mathrm{B}}\left(\Delta H_{\mathrm{fA}} \Delta H_{\mathrm{fB}}\right) /\left(\Delta H_{\mathrm{fA}} T_{\mathrm{B}}-\Delta H_{\mathrm{fB}} T_{\mathrm{A}}\right)
$$

In the case of enantiotropy, the low melting form is the thermodynamic stable form below the transition point, and above this point the high melting form is the thermodynamic stable form. The transition point can be low; close to $40{ }^{\circ} \mathrm{C}$ in the case of tolbutamide, close to $100^{\circ} \mathrm{C}$ in the case of propyphenazone or even higher than $200{ }^{\circ} \mathrm{C}$. Figure 8.11 illustrates the case of the reversible transition between polymorphs of tolbutamide, with reversible DSC heating and cooling curves.

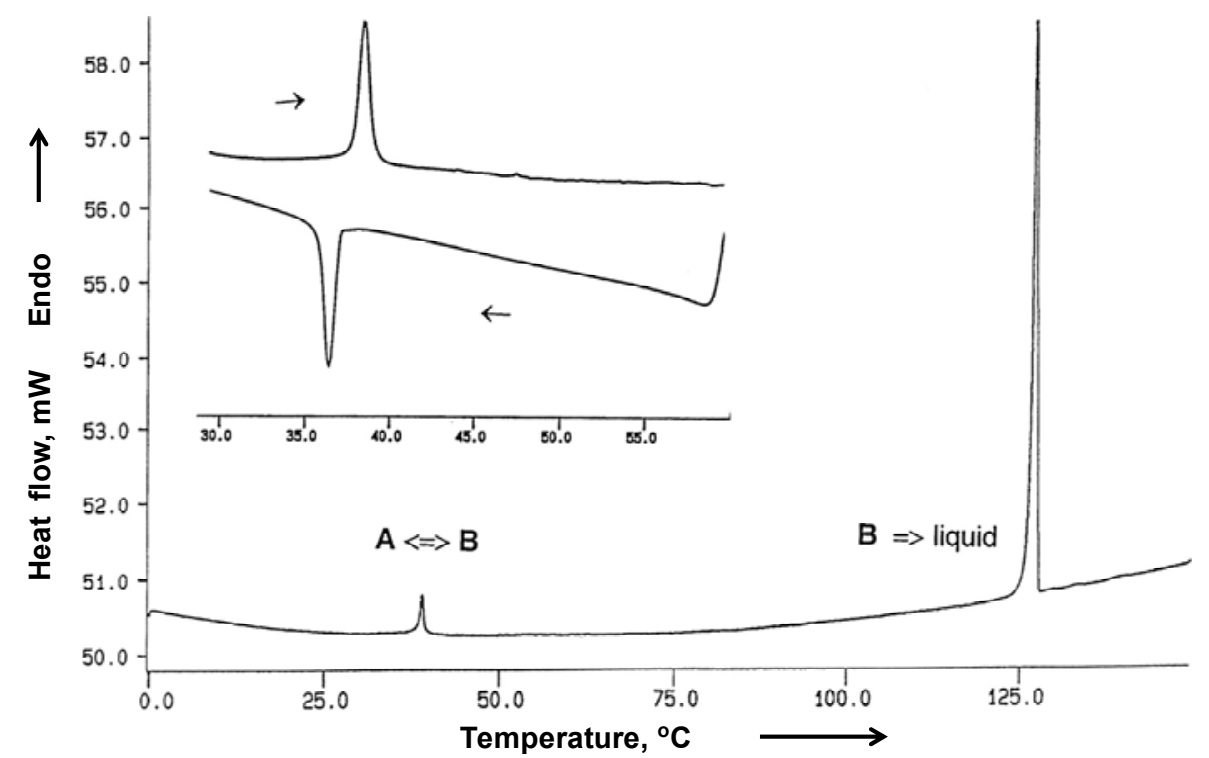

Figure 8.11. DSC curve for the reversible enantiotropic transition; Inset: heating and cooling curves in the temperature range of the transition

In the case of monotropy, there is only the high melting form present, which is the thermodynamic stable form within the entire range of temperatures. Sometimes a metastable form can behave as a stable form, and the DSC curve shows an exothermic transition before the melting of the stable form, helping to define the thermodynamically stable anhydrous form (see Figure 8.12).

Due to kinetics, metastable forms can appear and because different cases have to be taken into account, it is mandatory to use different heating rates for DSC experiments (see Section 8.4.3). For solid form selection it is absolutely necessary to know the temperature of the transition of enantiotropic systems, since it is a thermodynamic value. Does the transition take place at $20{ }^{\circ} \mathrm{C}, 30{ }^{\circ} \mathrm{C}, 70{ }^{\circ} \mathrm{C}$ or at $120^{\circ} \mathrm{C}$ ? What are the consequences for drug development? The temperature of the process, the temperature of storage and transport are important factors in production. 


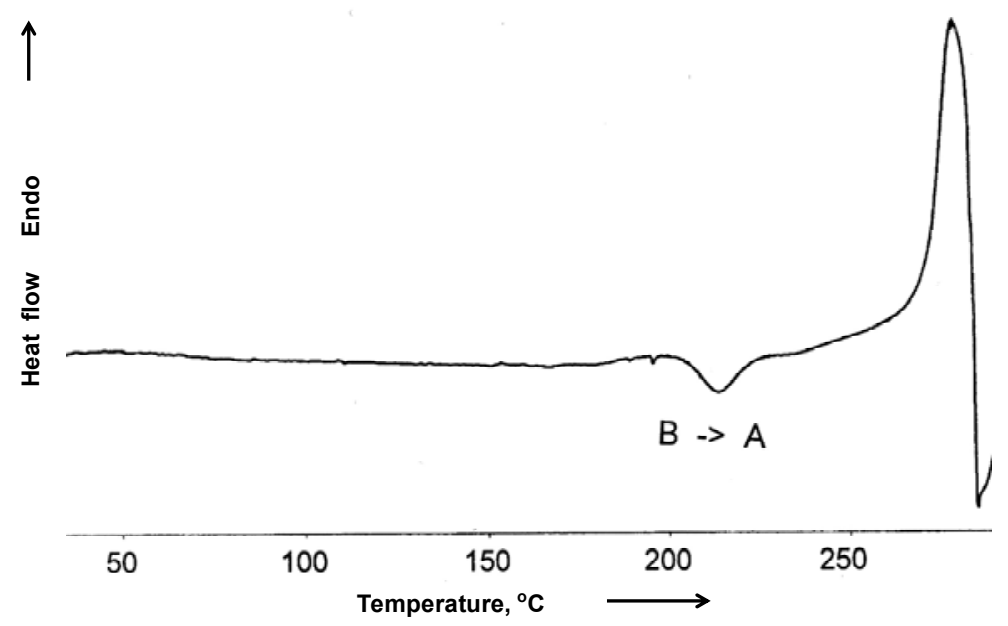

Figure 8.12. DSC curve of a metastable form which transforms in the stable form with exothermic transition (monotropy)

Due to kinetic behaviour, the temperature of transition observed in DSC is higher than the temperature observed by solubility measurements or slurry experiments in the presence of solvents. Table 8.4 shows some data obtained by calculation, according to Equation 8.6, compared to experimental data.

Table 8.4. Determination of enantiotropic transition temperatures for example substances by calculation and experiment

\begin{tabular}{ccc}
\hline Substance & Transition temperature, ${ }^{\circ} \mathbf{C}$ & Method \\
\hline \multirow{2}{*}{ Carbamazepine } & 71 & Calculation \\
& 73 & Solubility \\
\hline \multirow{2}{*}{ Nimodipine } & 82 & Calculation \\
& 88 & Slurry experiment \\
\hline \multirow{2}{*}{ Substance in development } & 39 & Calculation \\
& 25 & Slurry experiment \\
\hline
\end{tabular}

8.4.1.2. The phase diagrams of salts, solvates and hydrates

The phase diagrams of salts, solvates and hydrates are more complex because binary mixtures are often of different compositions. The new compound may undergo congruent melting (Figure 8.13a), or non-congruent melting (Figure 8.13b). Through heating, the melting of the solvate may be observed, followed by transformation to an anhydrous form, or the solvent may be involved in an endothermic transition into the anhydrous form. A series of such binary phase diagrams has to be considered if several compounds are formed. These diagrams are fundamental to the understanding of crystallisation and drying steps. Analytical investigations of solvates are not possible without thermogravimetry. Examples of DSC and TG curves corresponding at these behaviours are given in Figures 8.14 and 8.15. 

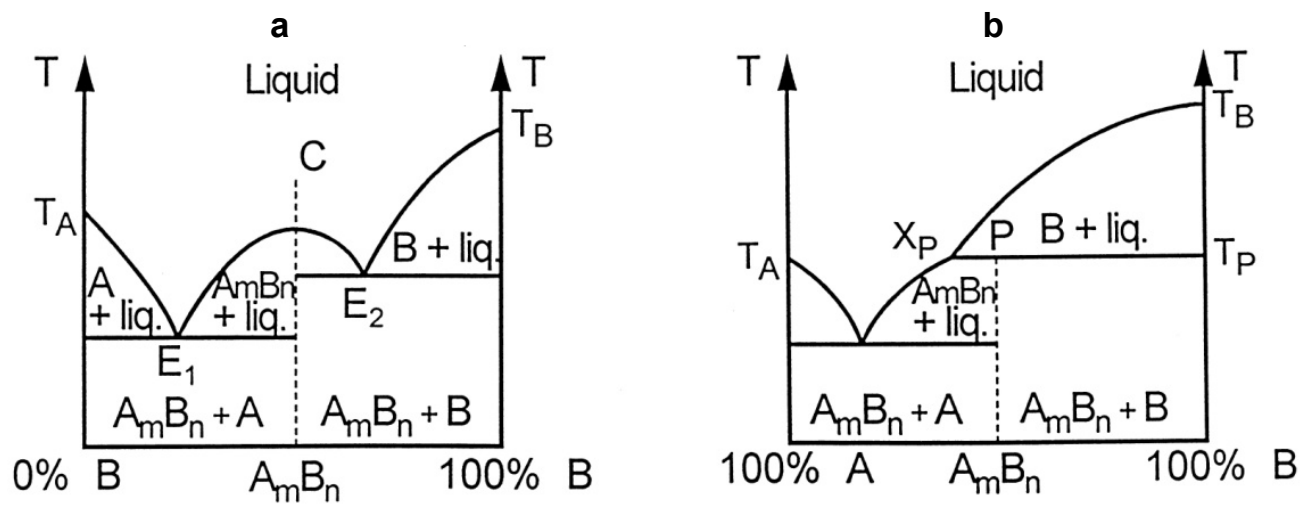

Figure 8.13. Binary phase diagrams (solvates, salts); (a) stable compound $\mathrm{C}$ and 2 eutectics; (b) non-congruent melting, peritectic behaviour, the compound dissociates

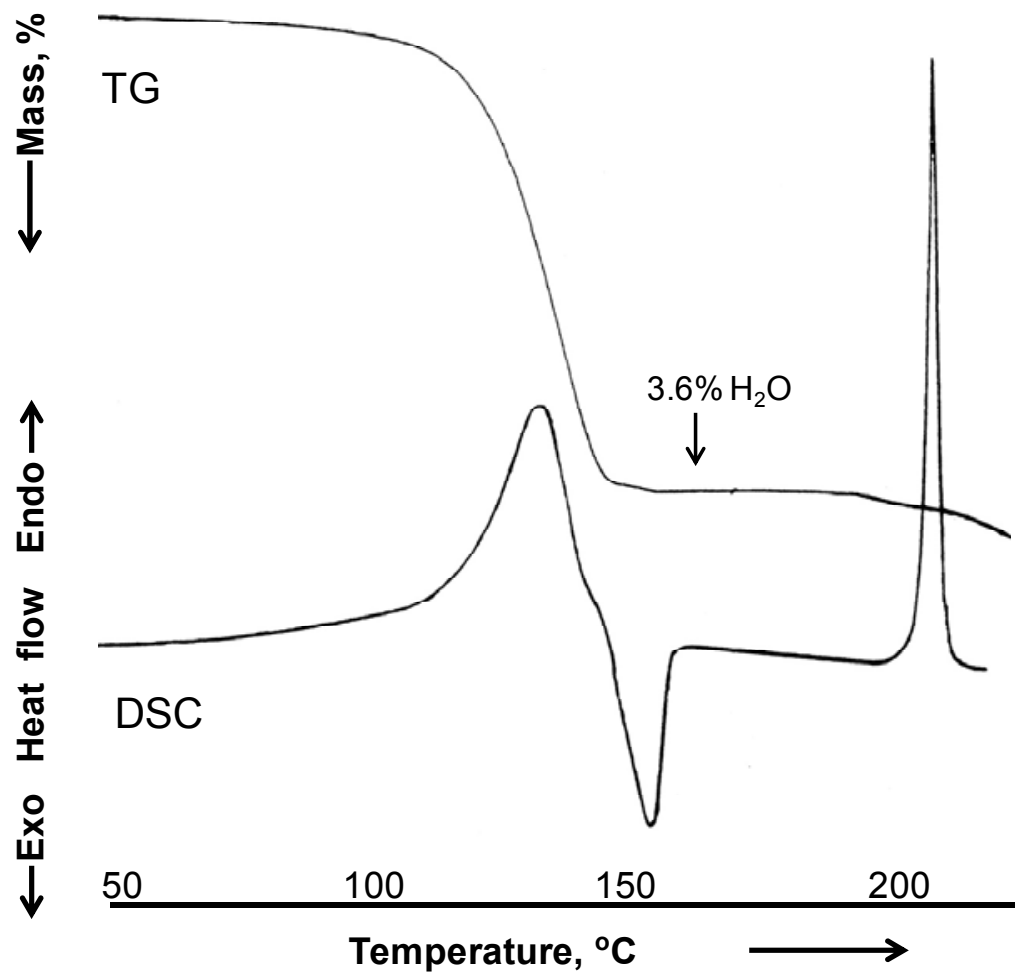

Figure 8.14. DSC and TG curves for congruent melting of the hydrate followed by loss of water and crystallisation into the anhydrous form

The effect of pressure on dehydration steps is exemplified by Figure 8.16 for copper sulphate pentahydrate. Depending on the pressure, dehydration can give the anhydrous form, the monohydrate or the trihydrate. This explains the coexistence of different steps of hydration during drying, milling or tableting. 


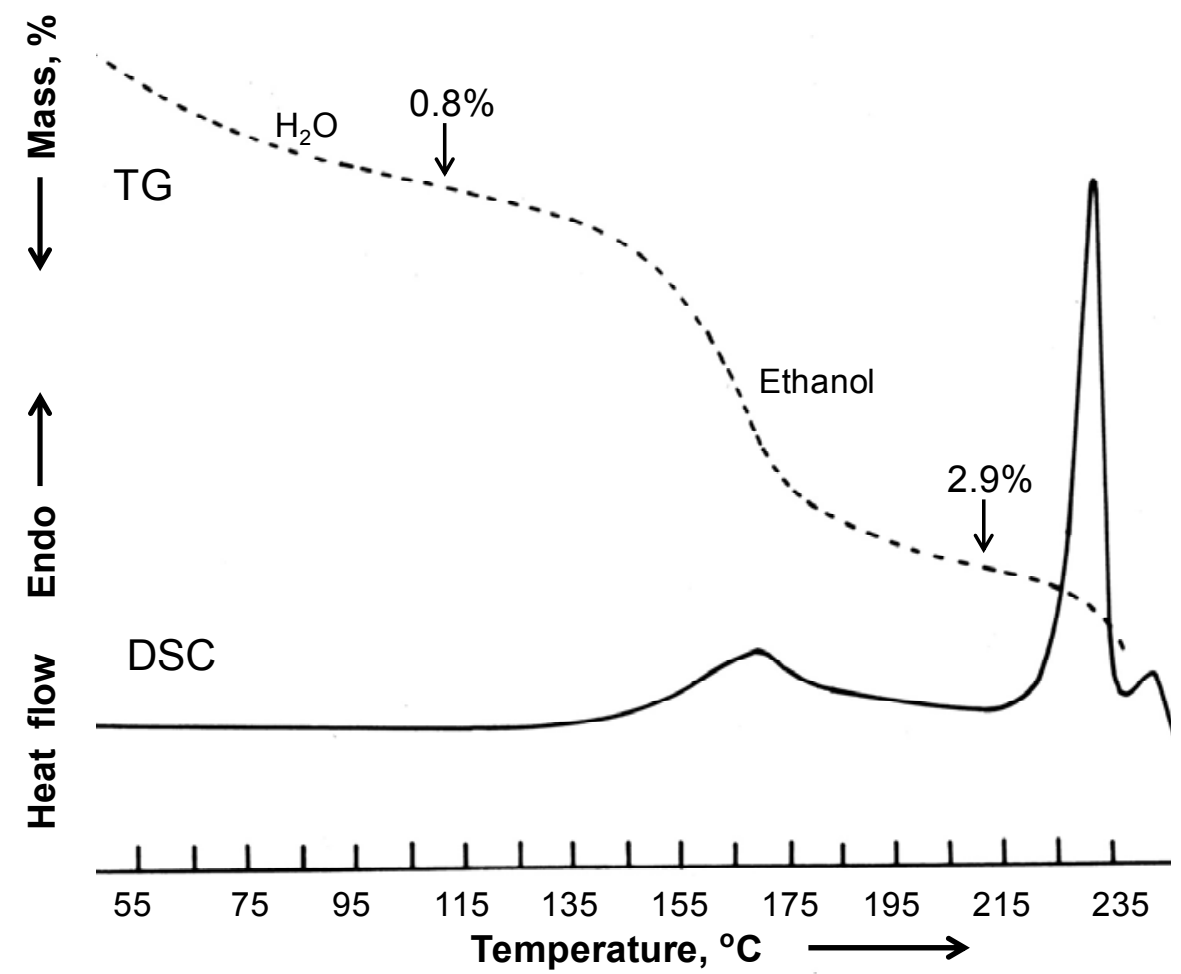

Figure 8.15. DSC and TG curves for a peritectic behaviour of a solvate: endothermic transition between the ethanol solvate and the anhydrous form

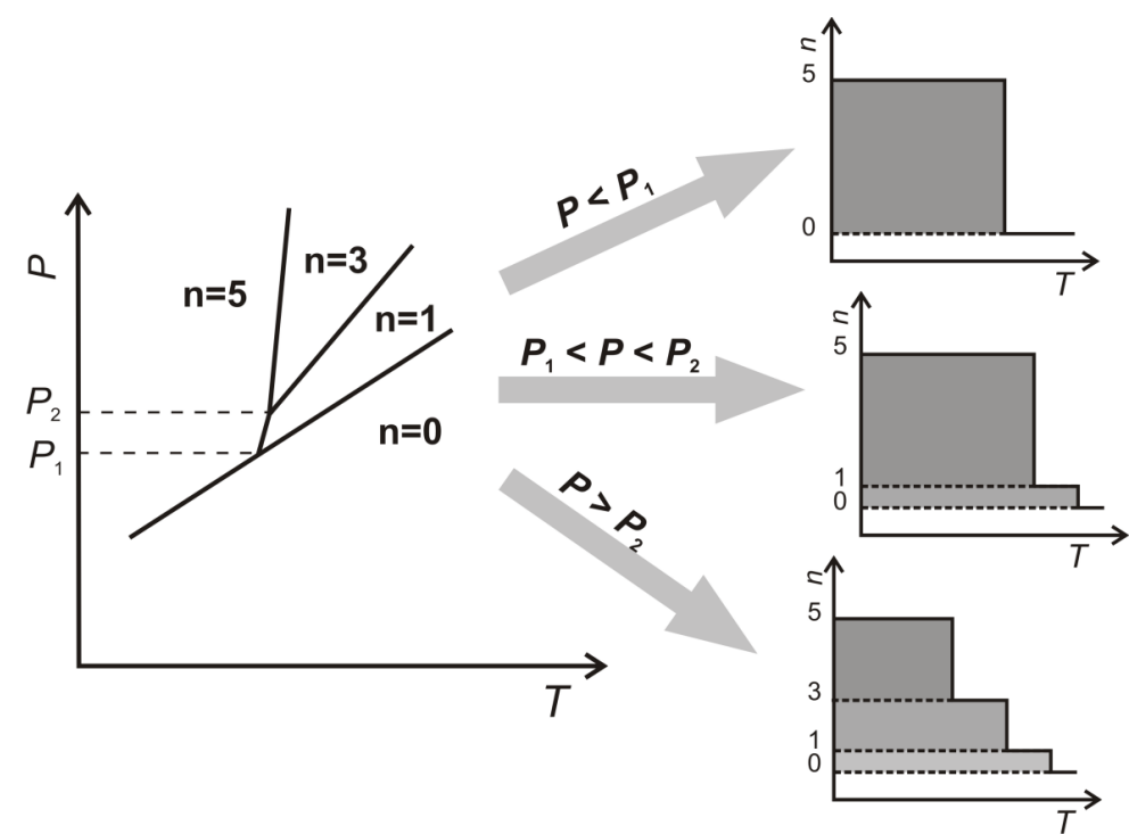

Figure 8.16. Effect of the pressure on the dehydration steps of copper sulphate pentahydrate: into trihydrate, monohydrate and anhydrous. Adapted from reference [29] 


\subsubsection{Amorphous state}

If a physical property of a crystalline substance is plotted against temperature, a sharp discontinuity occurs at the melting point. For amorphous substances there is no melting point, and a change of the baseline of the DSC curve occurs at the socalled glass transition temperature $T_{\mathrm{g}}$. Below this temperature, the amorphous phase has certain properties of a crystalline solid (e.g. plastic deformation) and is termed "glassy". At temperatures above $T_{\mathrm{g}}$, the substance retains some of the properties of a liquid, e.g. molecular mobility, and is termed "rubbery". Above $T_{\mathrm{g}}$, the increase in molecular mobility facilitates spontaneous crystallisation, with an exothermic enthalpy change after the glass transition (see Figure 8.17). The glass transition temperature is decreased by water, or other solvents and additives, facilitating crystallisation. The amorphous state is unstable, and the study of the glass transition with excipients under humidity, is a part of the pre-formulation process [30]. Amorphous solid phases are obtained either by melt quenching, if no degradation occurs during the melting, or by lyophilisation. They are easily detected by DSC, since the glass transition can be followed by the exothermic crystallisation into the crystalline state, or can be detected by XRD. Figure 8.18 shows a case where a very small amount of amorphous form was detected by DSC alone.

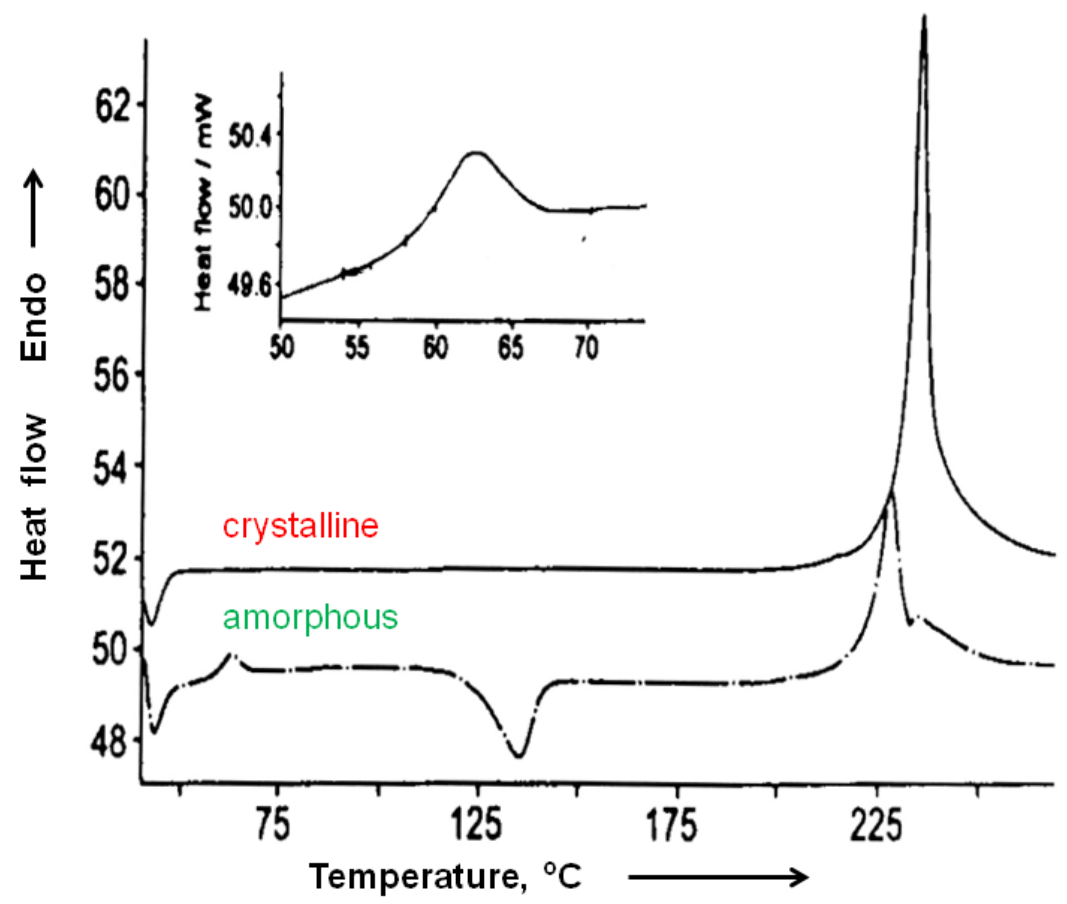

Figure 8.17. DSC curves of a crystalline and an amorphous hydrochloride salt of a substance. Inset: temperature range of the glass transition of the amorphous compound 


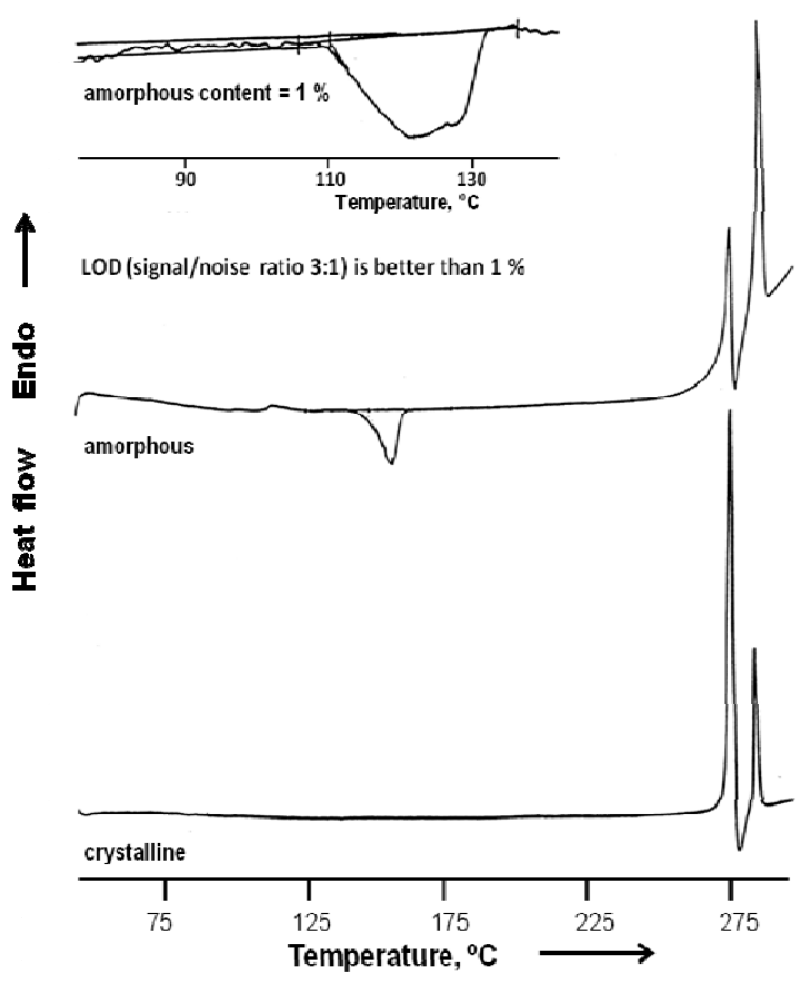

Figure 8.18. Detection of an amorphous part down to $1 \%$ in a drug substance with polymorphic behaviour.

\subsubsection{Purity determination}

As already described, the method for purity determination previously proposed [31] is particularly attractive as it does not require a reference standard. This method delivers absolute purity or assay value and results are obtained in less than 30 minutes. The determination of purity by means of DSC is based on the assumption that impurities depress the melting point of a pure material according to eutectic phase diagram behaviour. Figure 8.19a shows the phase diagram for the two component mixture with a eutectic point. At the eutectic point, for example $40 \% \mathrm{~A}, 60 \% \mathrm{~B}$, the crystals $\mathrm{A}$ and $\mathrm{B}$ melt together at the temperature $T_{\mathrm{E}}$ (Figure $8.19 \mathrm{~b}$ ), below the melting temperature of the pure compounds. If a mixture of $A$ and $\mathrm{B}$ (containing e.g. $90 \% \mathrm{~A}$ ) is heated, the melting of the eutectic mixture (which is $40 \% \mathrm{~A}$ ) is observed initially, until all of $\mathrm{B}$ is melted. During the melting of the eutectic mixture $(40 \% \mathrm{~A}, 60 \% \mathrm{~B})$ a part of $\mathrm{A}$ is melted with $\mathrm{B}$, with the corresponding amount of $A(2 / 3 \times 10 \%$, i.e. $6.66 \%$ of $A)$. As the temperature increases, pure A melts between $T_{\mathrm{E}}$ and $T_{\mathrm{m}}$ ( $T_{\mathrm{m}}$ being the end of the melting). For the corresponding DSC curve, if an endothermic heat flow at the eutectic temperature is observed, then the melting of crystals of A occurs. 

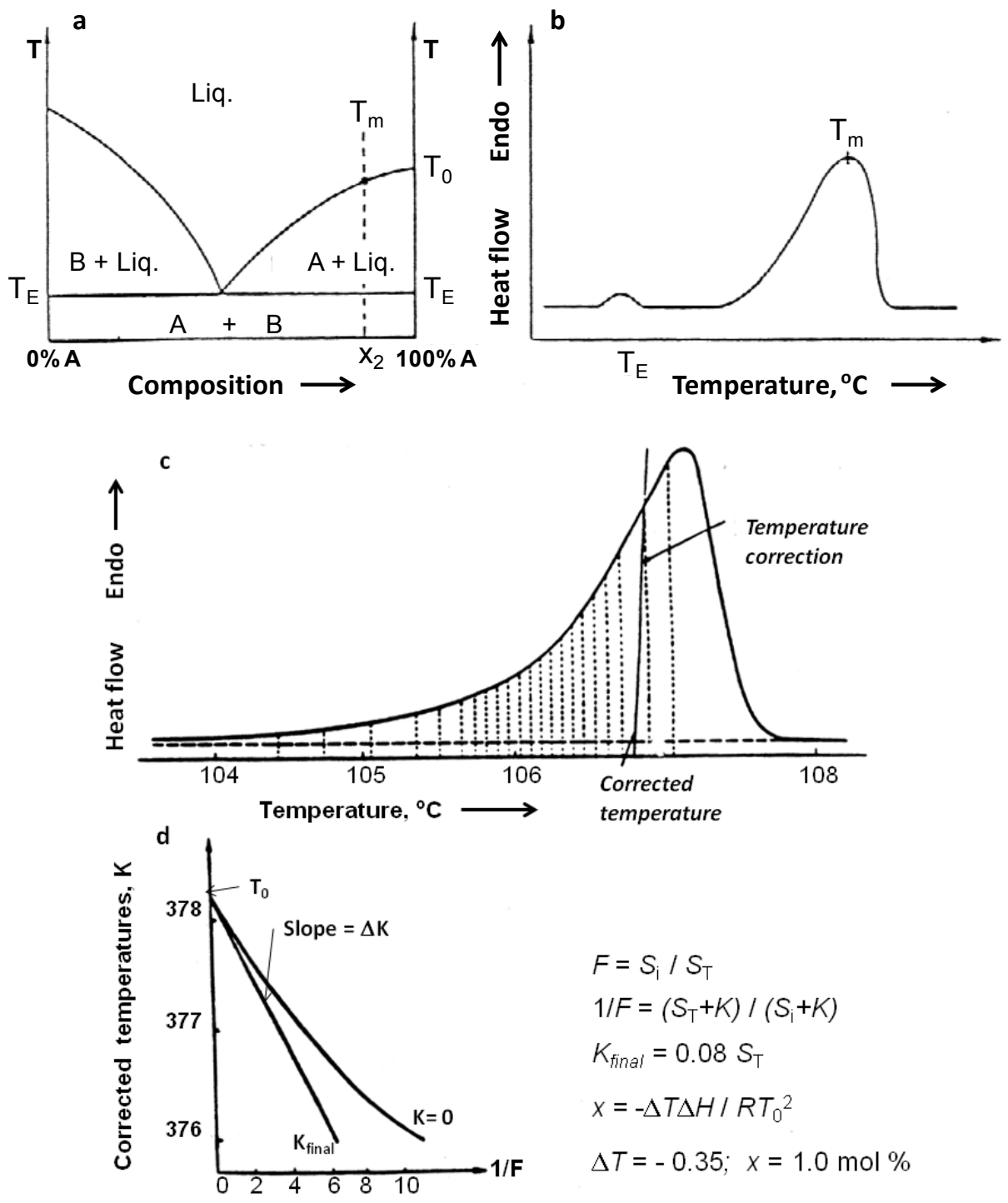

Figure 8.19. Purity determination by DSC

(a) phase diagram of the mixture of two compounds forming eutectic mixture, (b) DSC curve of the eutectic mixture,

(c) broadening of DSC curve during the melting of a substance after eutectic point, (d) a plot of observed analyte temperature $v s$. reciprocal value of the fraction melted.

The effect of impurity on the DSC curve is a melting depression and a broadening of the melting curve. The amount of impurities is calculated from the melting point depression $\Delta T=T_{\mathrm{o}}-T_{\mathrm{m}}$. The van't Hoff's law for diluted solutions is:

$$
x=\frac{-\Delta T \Delta H_{\mathrm{f}}}{R T_{0}^{2}}
$$


where $x$ is the mole fraction of impurities, $\Delta T$ the melting point depression, $\Delta H_{\mathrm{f}}$ the melting point of pure material, $T_{\mathrm{m}}$ the melting of the analyte, $T_{\mathrm{o}}$ the melting point of the pure compound and $R$ the gas constant.

The DSC procedure does not directly measure $\Delta T$, but can be used to calculate it from the melting curve. At the eutectic point all of $B$ is in the liquid phase. During the melting of $\mathrm{A}$, after the eutectic point, the concentration of $\mathrm{B}$ varies in the liquid phase. This causes the broadening of the DSC curve (Figure 8.19c). With no solid solution formation, the concentration of impurity in the liquid phase at any temperature during the melting is inversely proportional to the fraction melted at that temperature, and the melting-point depression is directly proportional to the mole fraction of impurity. A plot of the observed analyte temperature, $T_{\mathrm{i}}$, versus the reciprocal of the fraction melted $1 / F_{\mathrm{i}}$ at temperature $T_{\mathrm{i}}$, should yield a straight line with the slope equal to the melting-point depression $\left(T_{\mathrm{o}}-T_{\mathrm{m}}\right)$ (Figure 8.19d). The theoretical melting point of the pure compound is obtained by extrapolation to $\mathrm{l} / F_{\mathrm{i}}=0$ :

$$
T_{\mathrm{i}}=T_{0}-\frac{R T_{\mathrm{o}}^{2}\left(\frac{1}{F_{\mathrm{i}}}\right)}{\Delta H_{\mathrm{f}}} x
$$

The correction, $K$, has to be made corresponding to the part already melted in the eutectic, and the detected beginning of the melting curve. Figure $8.19 \mathrm{~d}$ depicts such a determination. Software from manufacturers mostly uses iterative linearisation which gives the best value of $K$.

Characteristics of the purity determination are as follows:

- impurities which have eutectic behaviour are measured (i.e. soluble in the liquid phase and insoluble in the solid phase),

- the sum of impurities should be $<2 \%$,

- the result is expressed in mole \% without knowledge of impurities,

- pure material is not needed,

- small amounts (0.1 - $2 \mathrm{mg}$ ) of material are used,

- if decomposition occurs during melting it can give erroneous results.

The calculation of purity allows the interpretation of the complex curves given by endotherms preceding the melting. It has been used successfully in stability studies at the beginning of development. An example is given in Section 8.4.4, Table 8.5.

\subsubsection{Kinetic aspects}

Every DSC study should include scans at different heating rates due to DSC being a dynamic method, and solid-state transformations, while being thermodynamically driven, are kinetically controlled. The DSC scans will differ if the sample under study is stable or metastable at ambient temperature. A typical set of DSC scans illustrates the study of the polymorphic relationship of two forms A and B. 
In the case of enantiotropy (Figure 8.20a):

Scan 1. The sample studied is the stable form A, which gives the endothermic solid phase transition $\mathrm{A} \rightarrow \mathrm{B}$ followed by the melting endotherm of form $\mathrm{B}$.

Scan 2. The sample studied is the stable form A, but for kinetic reasons the solid transformation $\mathrm{A} \rightarrow \mathrm{B}$ does not occur. Instead form $\mathrm{A}$ melts.

Scan 3. The sample studied is the stable form A which melts. Form B crystallises from the melt with an exothermic peak and form B melts at a higher temperature.

Scan 4. The sample studied is the metastable form B, which becomes stable at a temperature above the transition temperature. An exothermic peak corresponds to the solid transformation $\mathrm{B} \rightarrow \mathrm{A}$, followed by successive transformation $\mathrm{A} \rightarrow \mathrm{B}$, and melting of $\mathrm{B}$.

Scan 5. The sample studied is the metastable form B. The DSC scan shows its melting endotherm.

a

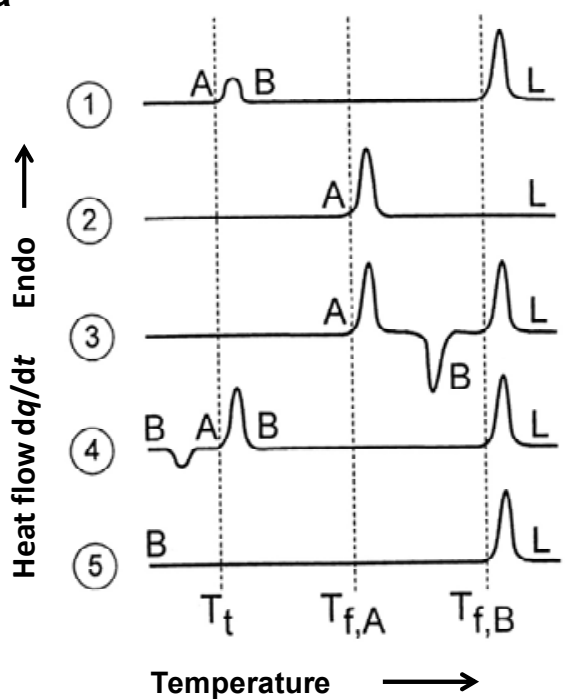

b

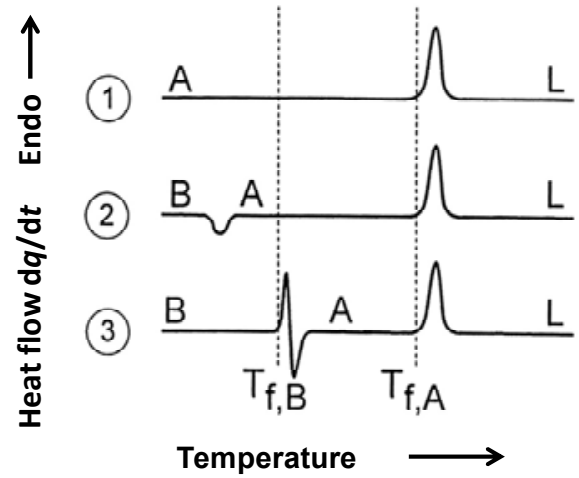

Figure 8.20. Possible DSC scans for 2 polymorphs. (a) enantiotropy; (b) monotropy

In the case of monotropy (Figure 8.20b):

Scan 1. The sample studied is the stable form A, and its melting endotherm is observed.

Scan 2. The sample studied is the metastable form B, which transforms exothermically in the solid state into the stable form A. Form A melts at a higher temperature.

Scan 3. The sample studied is the metastable form $B$, which does not transform into A, but melts endothermically. From the melt the stable crystalline form A appears, with an exothermic peak, then A melts at a higher temperature. 
Similar interpretations apply to all methods that involve heating (e.g. hot stage optical microscopy, hot stage infrared or Raman microscopy, temperature resolved or variable temperature XRD).

It is difficult to distinguish between enantiotropy and monotropy in the cases of Figure 8.20a, Scan 5 and Figure 8.20b, Scan 1, as well as in Figure 8.20a, Scan 3 and Figure $8.20 \mathrm{~b}$, Scan 3. The interpretation of the DSC curves is facilitated by Burger's enthalpy of fusion rule [27-28]: if the higher melting form has the lower melting enthalpy, then both forms are related enantiotropically. As demonstrated in Figure 8.21, for a benzisoquinoline hydrochloride [12], the melting enthalpy of the higher melting form B is lower than the melting enthalpy of $A$. Therefore, the two forms are enantiotropically related, with form A being stable below the transition point. Modification B is hygroscopic and undergoes a solvent-mediated transition to form $\mathrm{A}$ in alcohols at ambient temperature.

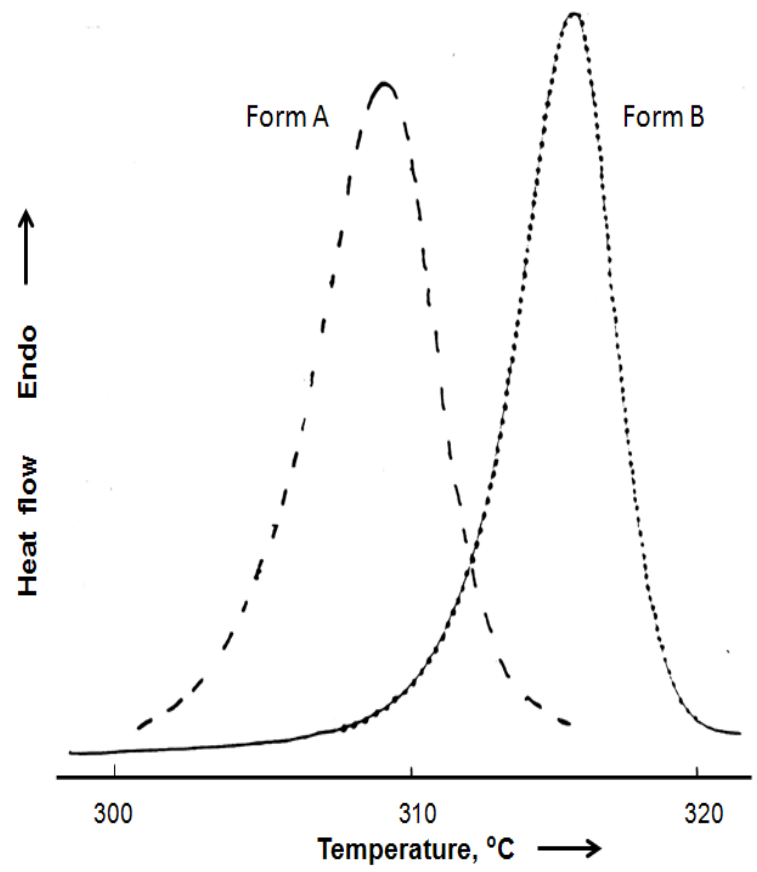

Figure 8.21. Polymorphic behaviour of a benzisoquinoline hydrochloride. Each form has its melting curve. Enantiotropy demonstrated by the Burgers'rule. Form A on the left side has a melting point of $304{ }^{\circ} \mathrm{C}$ and a melting energy of $50 \mathrm{~kJ} \mathrm{~mol}^{-1}$. Form B has a melting point of $311^{\circ} \mathrm{C}$ and a melting energy of $46 \mathrm{~kJ} \mathrm{~mol}^{-1}$ [14]

Figure 8.22 shows DSC curves of propyphenazone. Samples from two manufacturers were investigated in our laboratory since the second sample did not comply with melting requirements. An unexpectedly high melting point was not due to higher purity, but to the enantiotropic behaviour. The second sample contained traces of a high melting form. A slower heating rate showed for both samples two endotherms. DSC experiments allowed the manufacture in situ of the 
high melting form, and to characterise it completely including solubility and dissolution rate $[12,13]$. For examples of kinetic effects due to polymorphism and salts, see references [32,33]. Kinetics also governs the steps of hydration and dehydration in the solid state, giving rise to complex conversion relationships [34-36], (see example in Figure 8.25).

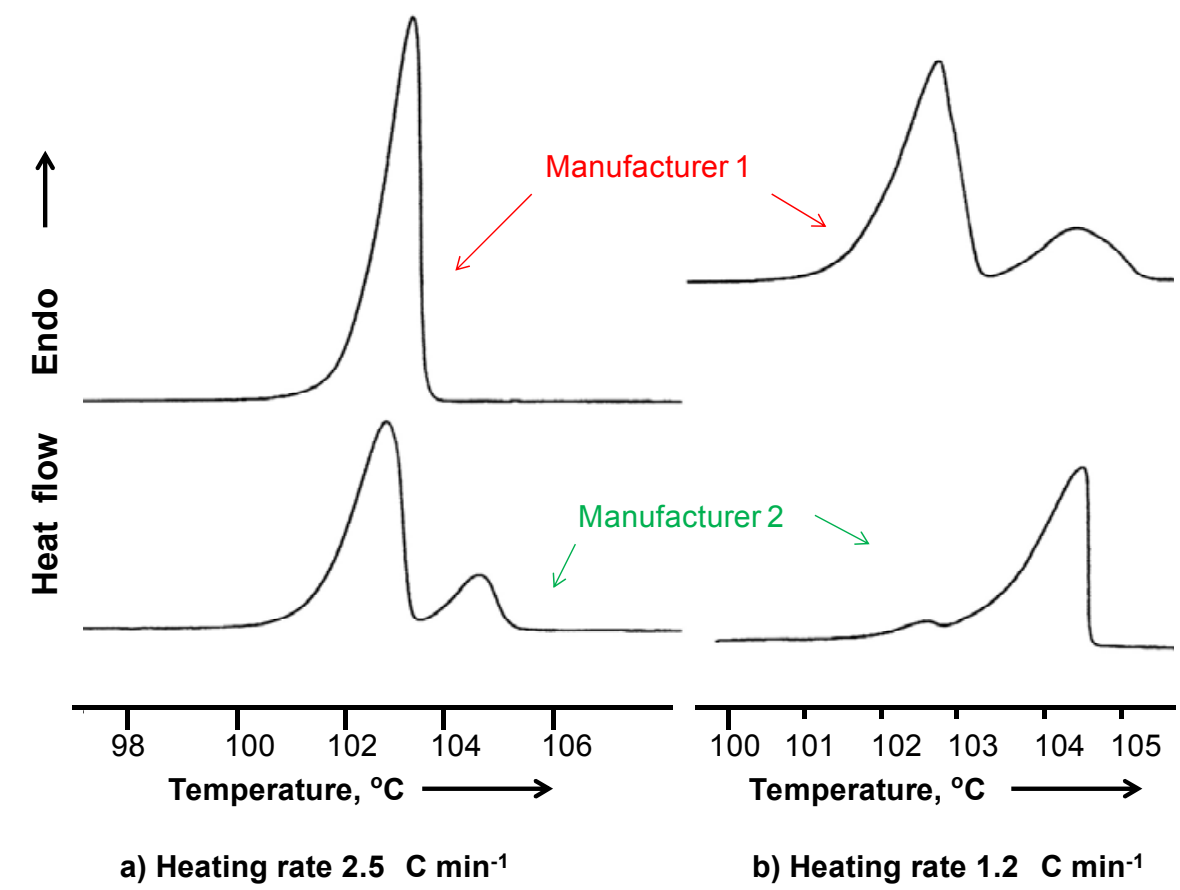

Figure 8.22. Effect of heating rate on the DSC of propyphenazone enantiotropic system. Batch 1 and 2 of two manufacturers have different melting points. At high heating rates $\left(20,10,5\right.$, or $\left.2.5^{\circ} \mathrm{C} \mathrm{min}^{-1}\right)$ batch 1 shows only one peak. Batch 1 is a pure form, batch 2 contains very small amounts of high melting form which acts as seed. With slow heating rates transformation to the high melting form occurs for both batches [12]

\subsubsection{Sorption isotherms and hydrates}

Most drug substances crystallise in the form of solvates or hydrates. The DSC/TG curves allow us to follow the desolvation process. It is possible to measure water sorption isotherms by TG in controlled atmospheres. Often the instrument used is an automatic multi-vapour gravimetric sorption analyser, a so-called "dynamic vapour system" (DVS), e.g. those made by Surface Measurement Systems Ltd. Figure 8.23 shows such curves for an enantiotropic drug substance which absorbs water to form a trihydrate. The desorption occurs with hysteresis, allowing us to define the relative humidity range for each form. According to the curves, the trihydrate form would be possible to develop. However, it was not possible to manufacture it as a pure form in the process. The enantiotropic form, which was stable at room temperature, could be manufactured and stored in tight containers [14]. 


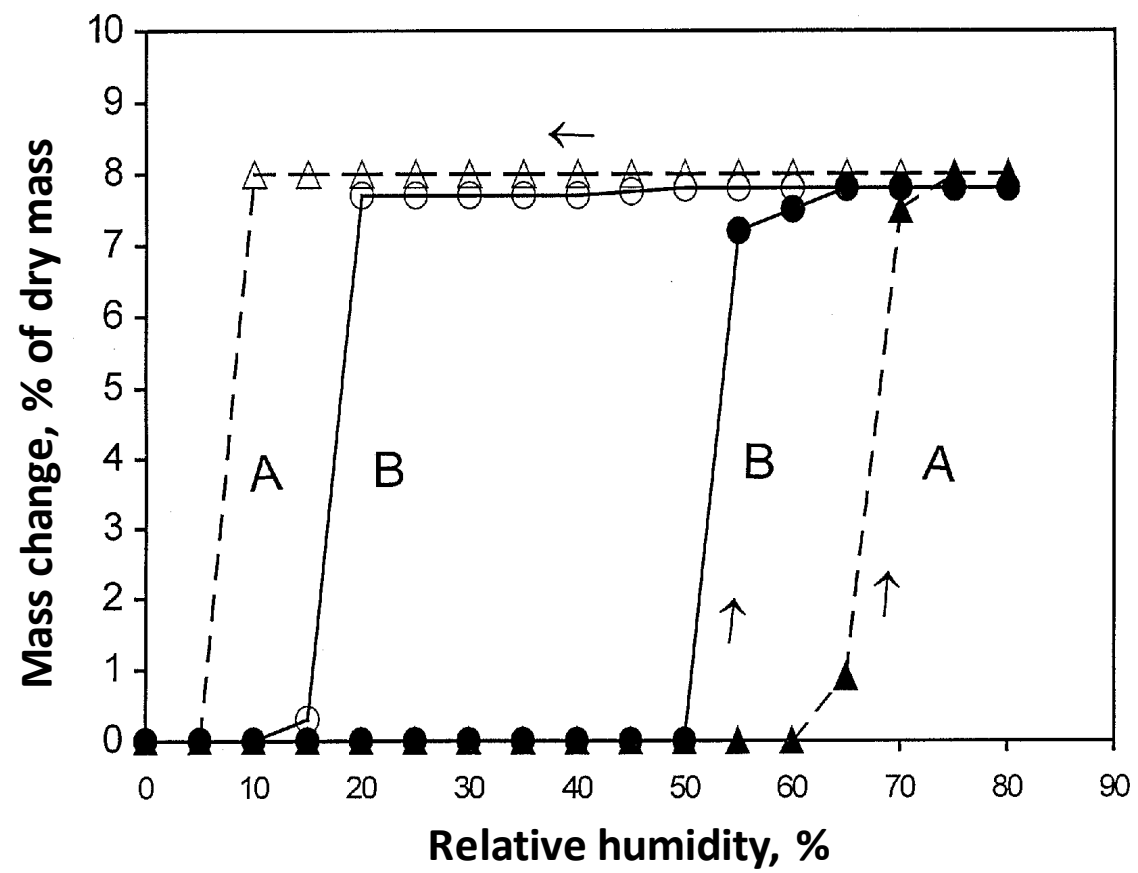

Figure 8.23. Example of a water sorption-desorption isotherm for two enantiotrops (A and B) and a trihydrate of the investigated compound

Figure 8.24 shows the use of sorption isotherm measurement for a salt selection. The hydrochloride first selected was too hygroscopic for easy development, and therefore new salts were studied. The DSC purity was determined for stability comparison (Table 8.5). The hydrogen fumarate and hydrogen tartrate were attractive due to their good hygroscopic behaviour, however the stability results clearly showed that hydrogen tartrate was chemically stable. This example demonstrates the advantageous use of thermal techniques for quick decisions in early development.

Table 8.5. DSC purity results for the stability comparison of salts given in Figure 8.24.

\begin{tabular}{cccc}
\hline \multirow{2}{*}{ DSC time } & \multicolumn{3}{c}{ DSC purity, \% } \\
\cline { 2 - 4 } & $\begin{array}{c}\text { Hydrogen } \\
\text { fumarate }\end{array}$ & $\begin{array}{c}\text { Hydrogen } \\
\text { maleate }\end{array}$ & $\begin{array}{c}\text { Hydrogen } \\
\text { tartrate }\end{array}$ \\
\hline Initial & 99.8 & 99.8 & 99.9 \\
\hline 1 week & 99.4 & no peak & 99.9 \\
\hline Luminous exposure: $1200 \mathrm{klux} \mathrm{h}$ & 99.1 & 97.6 & 99.5 \\
\hline
\end{tabular}


a
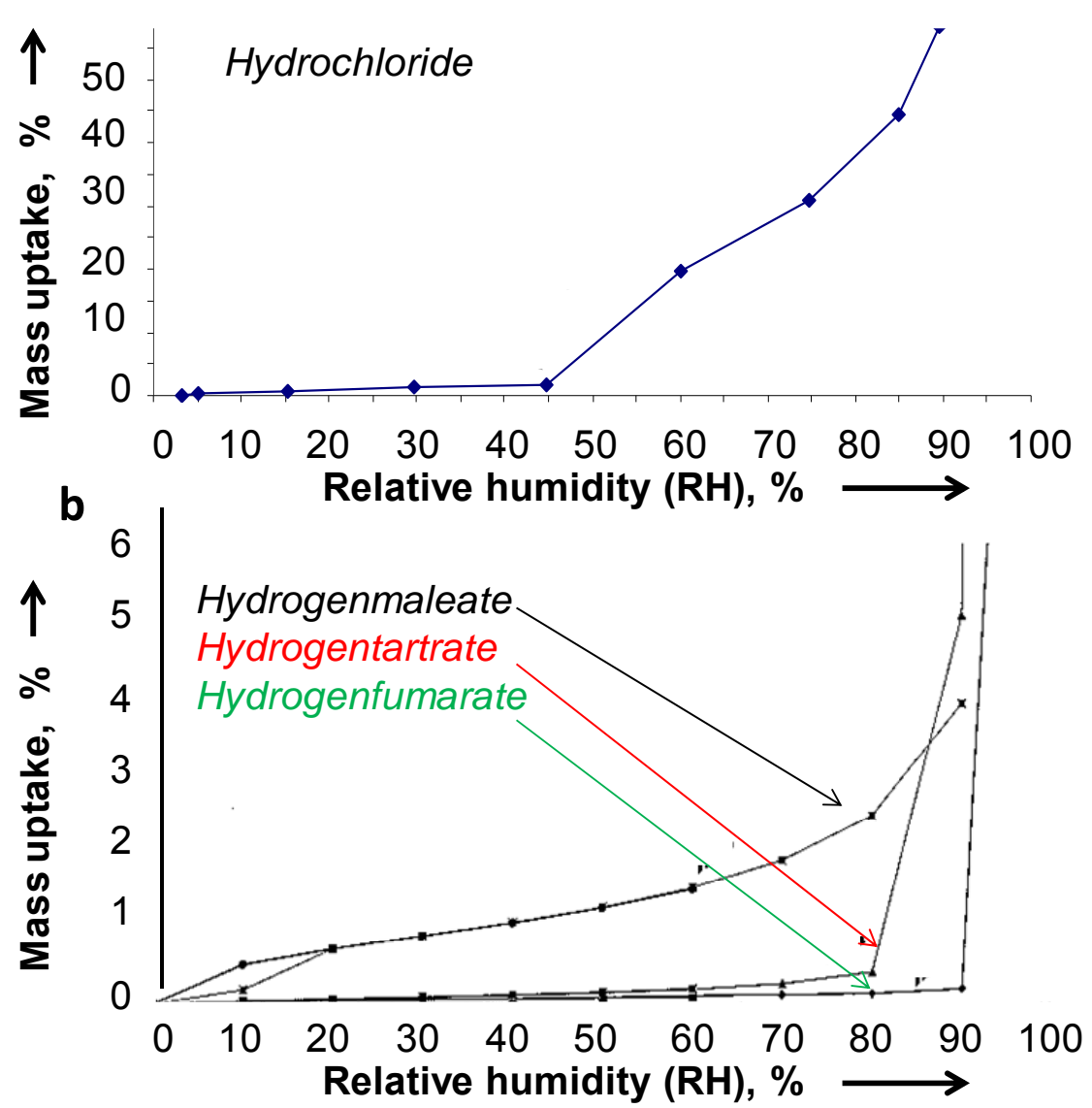

Figure 8.24. Salt selection. The hygroscopic hydrochloride is replaced by the hydrogen tartrate [18]. (a) Dynamic vapour system (DVS) curves of hydrochloride,

(b) DVS curves for hydrogenmaleate, hydrogenfumarate and hydrogentartrate salts

It is recommended that several cycles of sorption and desorption are performed when a hydrate is produced. Figure 8.25 shows the kinetic effect of seeds for a drug substance. The anhydrous form is converted to the monohydrate at a relative humidity of RH $>90 \%$. After the desorption, traces of monohydrate are present and the substance absorbs water very fast. The behaviour was also found in stability studies of batches of the drug [32].

Recently introduced automatic systems bring a faster understanding of complex hydration and dehydration behaviour, as well as their kinetics with monitored relative humidity (RH \%). Instruments for research have $0.1 \mu \mathrm{g}$ sensitivity, and less than $10 \mathrm{mg}$ of sample can be used. By using solvent vapours, solvated forms can be manufactured and studied. These studies are a prerequisite for the microcalorimetric analysis of amorphous content. 


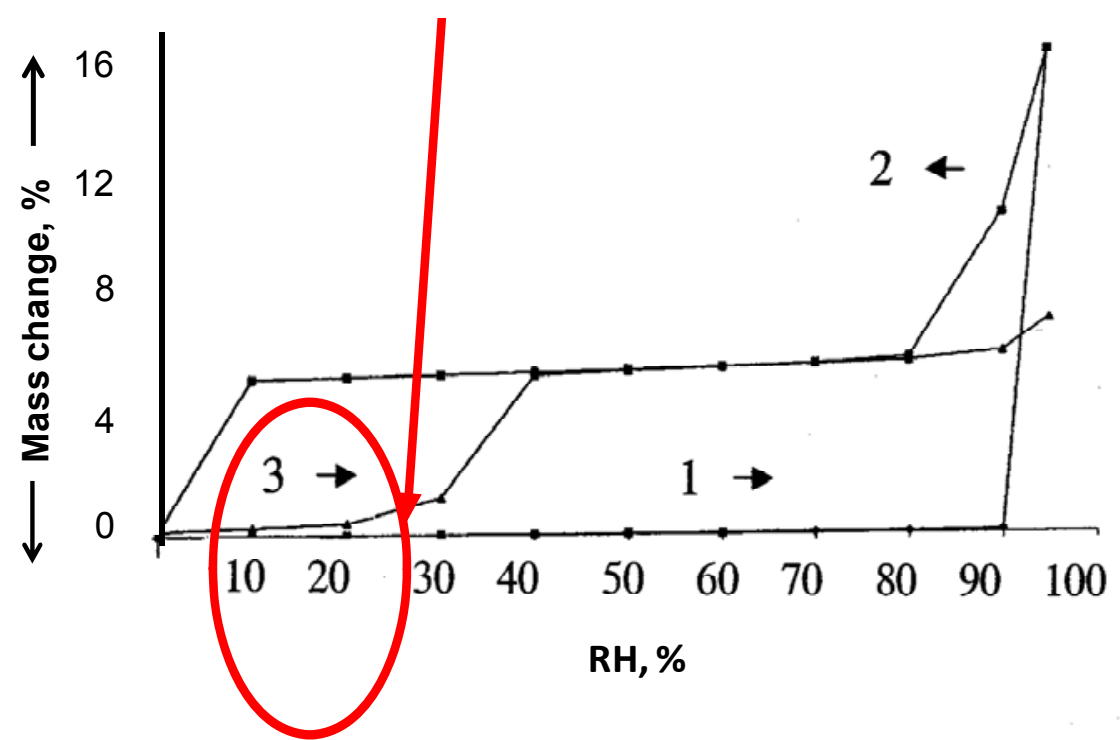

Figure 8.25. Water sorption-desorption isotherms and kinetics. In the first cycle the substance takes up water only at $\mathrm{RH}>90 \%$. After the desorption cycle the third absorption cycle shows the transformation into the monohydrate already at $30 \% \mathrm{RH}$

\subsubsection{Combined techniques}

\subsubsection{Combination of DSC and XRD}

XRD instruments are equipped with heating cells and are routinely used in most research laboratories. X-ray patterns of pure forms obtained in situ can be used for modelling, and in favourable cases, for crystal structure determination. Figure 8.26 exemplifies the combination of DSC/XRD for an enantiotropic system with heating and cooling curves. The advantage of coupled instruments developed in a research laboratory has been demonstrated [37]. The trehalose monohydrate dehydration and hydration were studied in a humid atmosphere as an application of a new commercial instrumentation [38].

8.4.5.2. Thermogravimetry-mass spectrometry (TG-MS) and thermogravimetryinfrared spectroscopy (TG-IR)

An example of TG-MS is given for calcium oxalate in Figure 8.27, where water, CO and $\mathrm{CO}_{2}$ are positively identified. Figure 8.28 is an example of the successful interpretation of a crystallisation into solvates followed by desolvation to a metastable form. The DSC and TG-MS in this figure correspond to the methanol solvate. Similar pictures are obtained with other solvates e.g. acetone and ethanol. The DSC/TG/TG-MS and temperature resolved XRD experiments, as well as slurry experiments, were necessary to understand the crystallisation of this drug substance and to change the solvent of crystallisation [32].

Figure 8.29a shows the DSC/TG for aspartame hemihydrate and corresponding IR spectra (Figure $8.29 \mathrm{~b}$ ). The first endotherm at around $130{ }^{\circ} \mathrm{C}$ is the loss of 

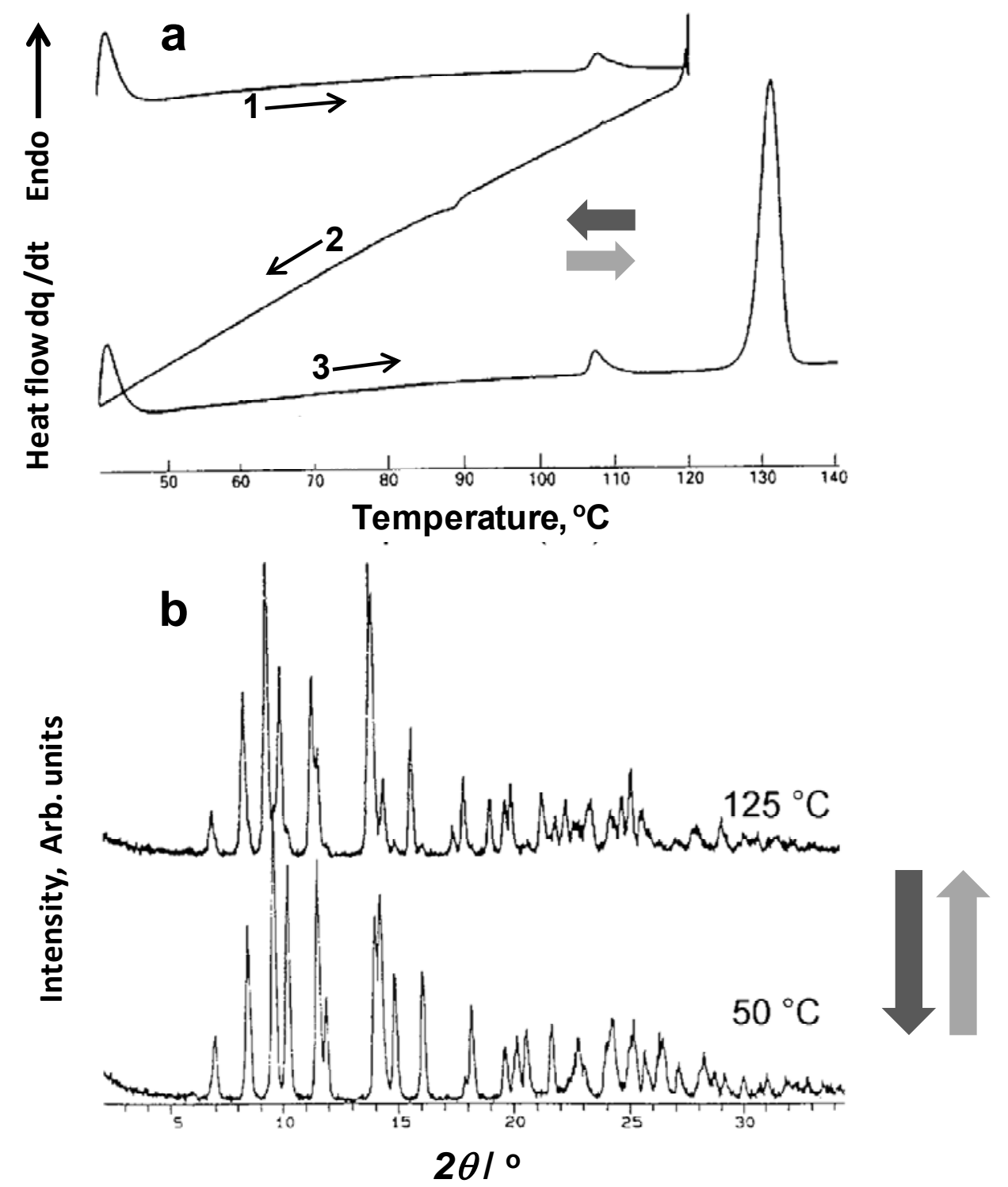

Figure 8.26. Use of combined DSC-XRD for the detection of a reversible enantiotropic transition of a purine derivative; (a) successive DSC heating up to $120^{\circ} \mathrm{C}$ (1) cooling (2) and heating up to $140{ }^{\circ} \mathrm{C}$ showing the reversible phase transition and the melting (3); (b) reversible transition between 50 and $125^{\circ} \mathrm{C}$ followed by XRD

water, and the sharp endotherm is due to decomposition and formation of methanol [14]. Solvates can be successfully characterised [39], and quantitative information of the spectroscopic signal is possible [40].

An example is given in Figure 8.30 of the interpretation of the behaviour of a malonate using several combined technologies: DSC, TG, TG-MS, temperature resolved XRD and IR. Through drying, the malonic acid can sublimate and the 

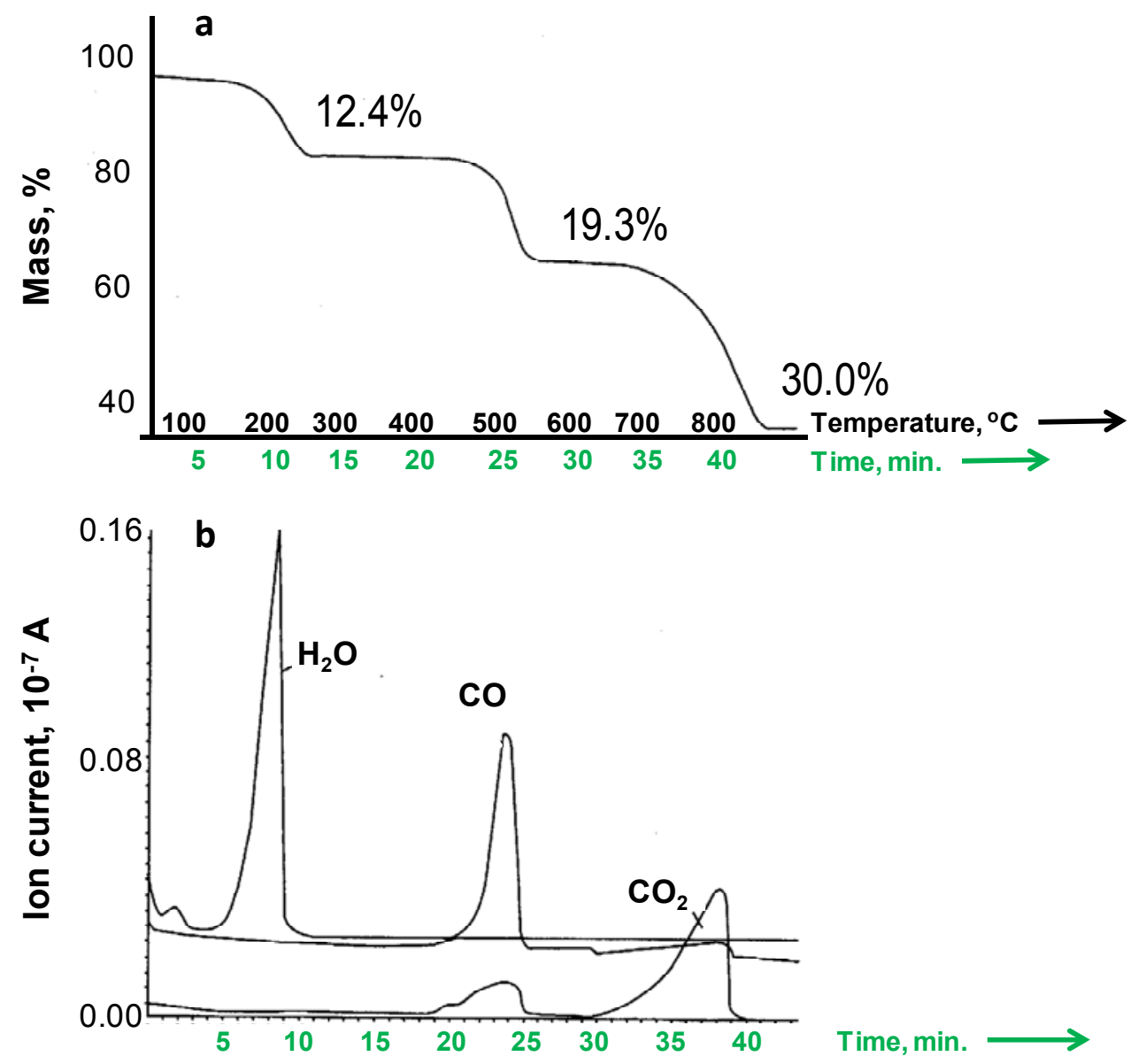

Time, $\min$.

Figure 8.27. (a) TG curve of calcium oxalate and (b) MS signals of $\mathrm{H}_{2} \mathrm{O}, \mathrm{CO}$ and $\mathrm{CO}_{2}$

base formed [14]. Another example, given in Figure 8.31, deals with the loss of water from a drug substance during drying. The decomposition product formed was at first believed to be a new form. DSC/TG/XRD and IR were then successfully used for the identification of the substance with two enantiotrops [15]. The DSC of the stable form shows an enantiotropic transition. After the melting of the second form, a degradation into the lactam with the loss of a molar quantity of water was detected by TG-MS and temperature resolved XRD. The IRheating cell allowed the structure of the lactam to be confirmed. 


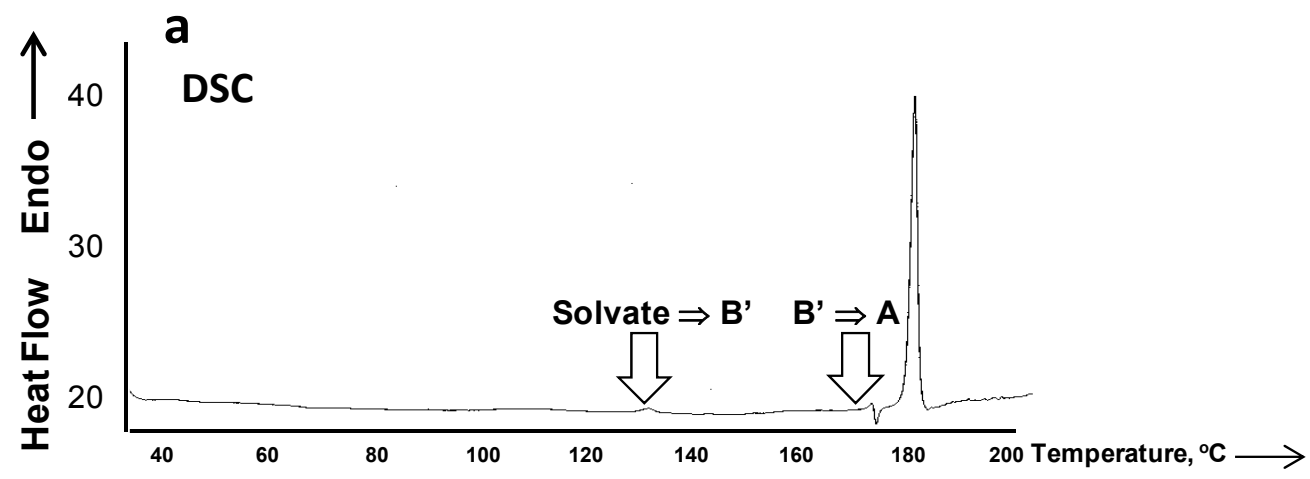

b

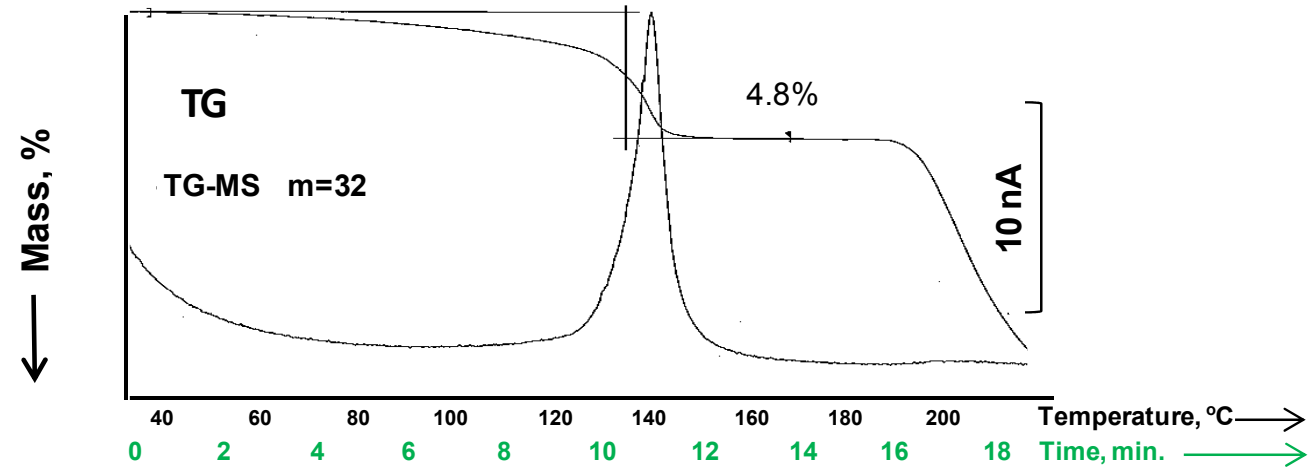

Figure 8.28. Identification of a methanol solvate in a complex crystallisation behaviour by TG-MS; (a) DSC curve and (b) TG curve and corresponding MS signal [14]
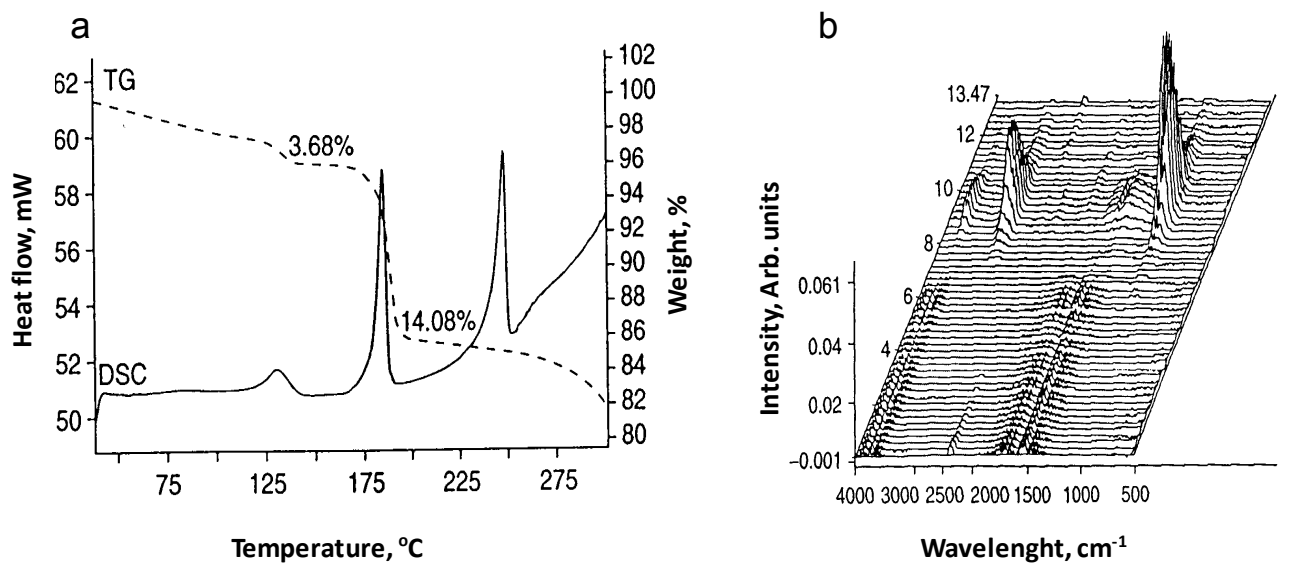

Figure 8.29. Use of TG-IR for the detection of methanol in the degradation of aspartame; (a) TG and DSC curves, (b)corresponding IR spectra 
a

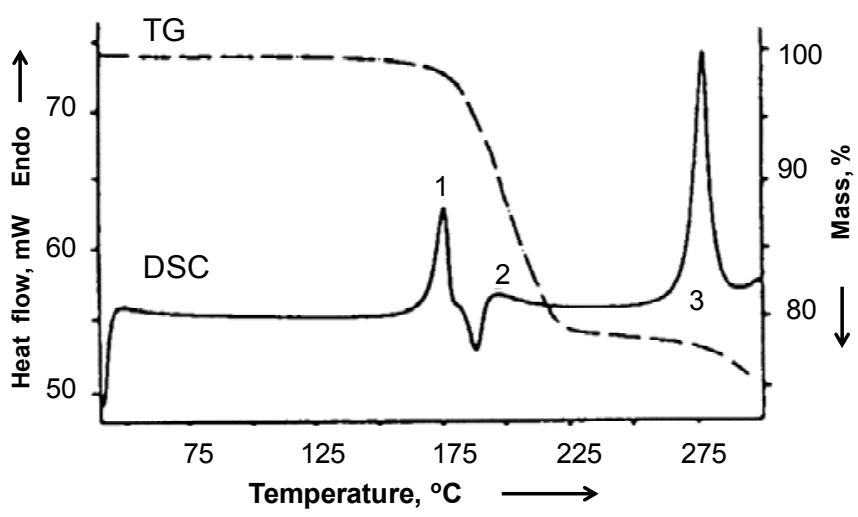

b
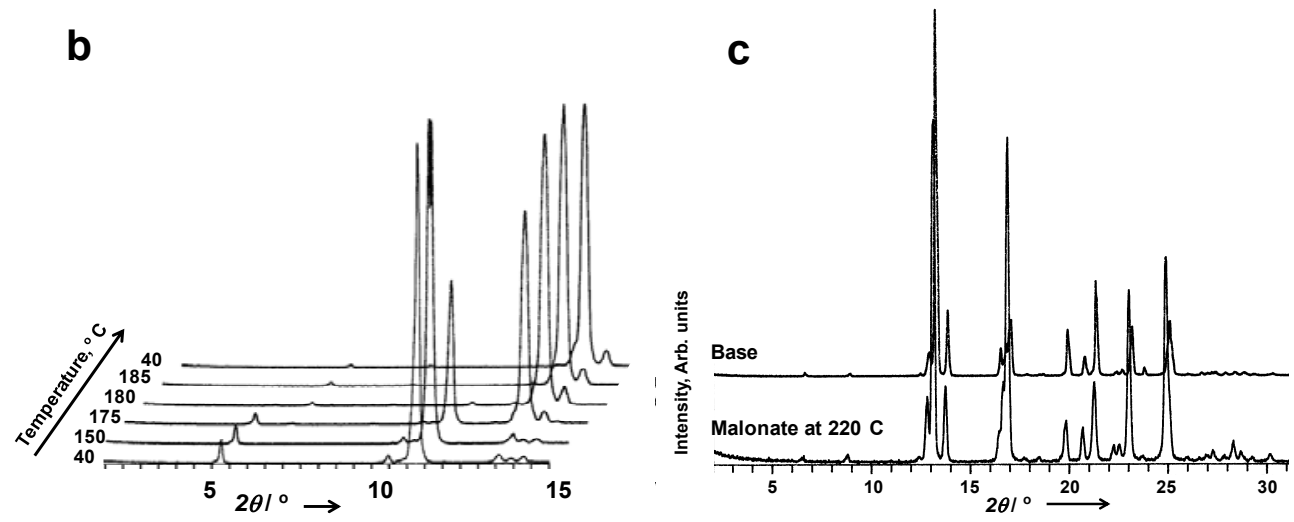

d
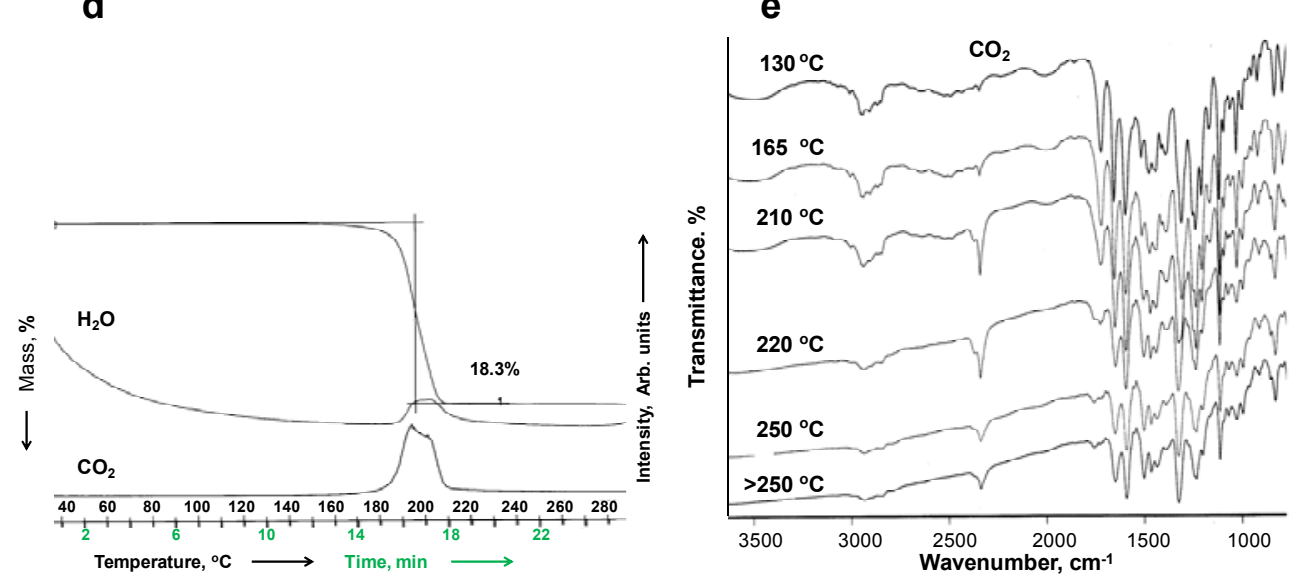

Figure 8.30. Use of combined techniques for the interpretation of thermal events of a

malonate. (a) DSC and TG curves. Three different DSC peaks are interpreted as melting (1) and decomposition (2) of the malonate followed by melting of the base (3);

(b) temperature resolved XRD shows the irreversible transformation into the base according to (c); (c) XRD patterns of the free base and malonate; (d) TG-MS experiment indicates the evolution of water and $\mathrm{CO}_{2}$ during heating of malonic acid;

(e) IR spectra taken at different temperatures confirm the presence of $\mathrm{CO}_{2}$ and the chemical structure of the base [14] 
a

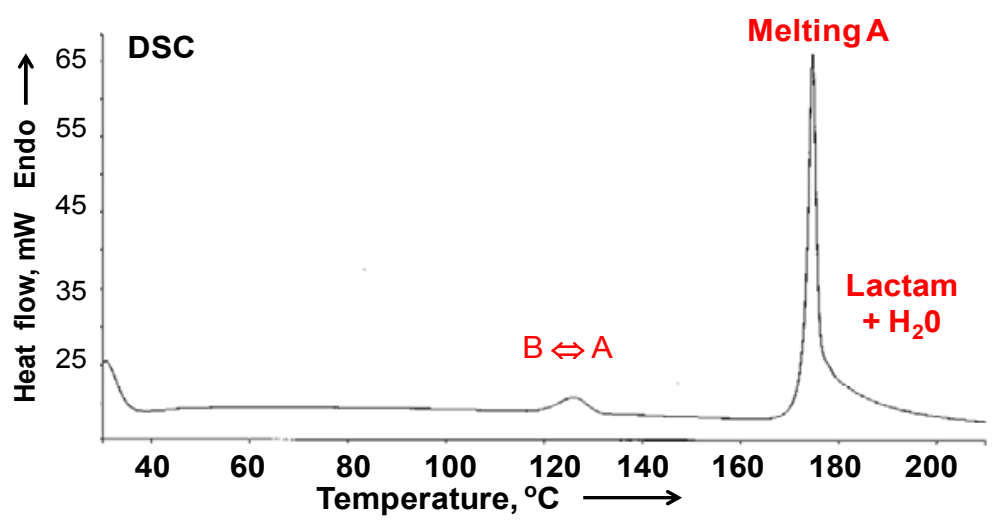

b

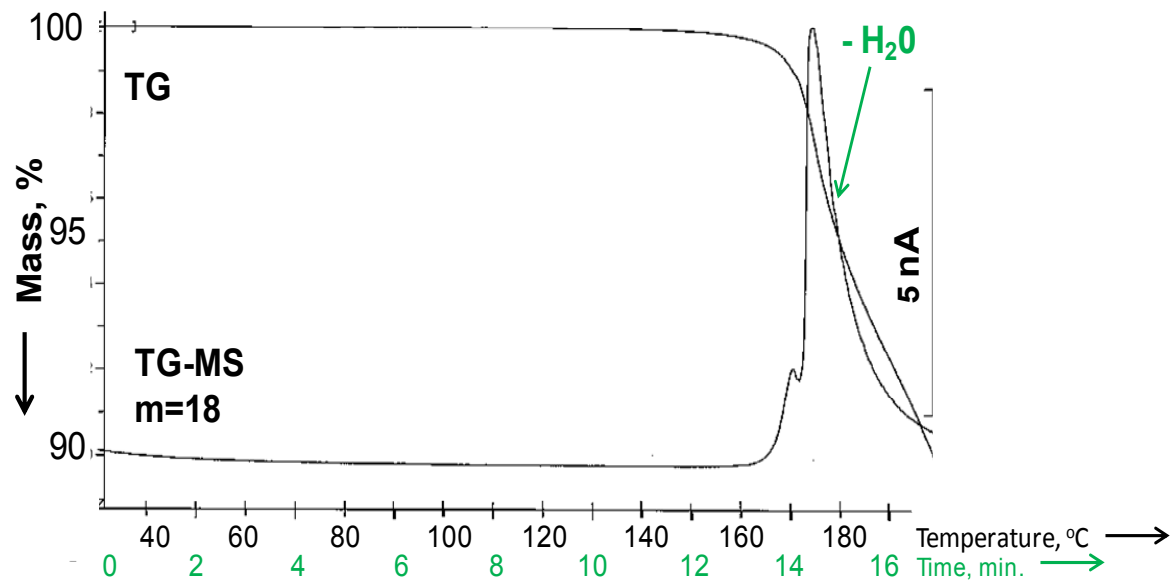

C

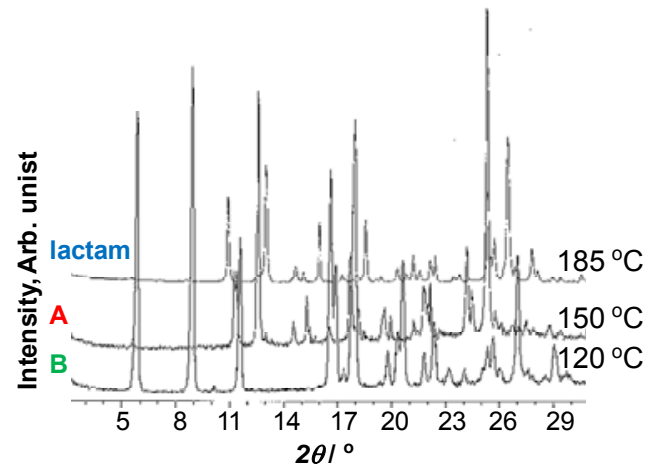

d

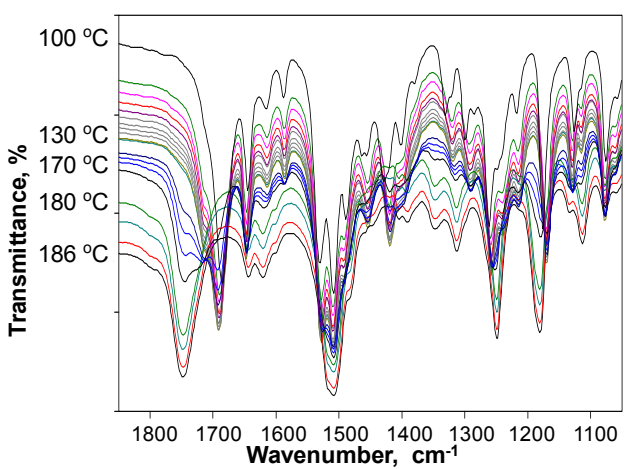

Figure 8.31. Combined techniques elucidating the decomposition of an enantiotropic drug into a lactam [15]. (a) DSC curve; (b) TG-MS confirms the degradation with loss of water; (c) the temperature resolved XRD shows the 3 steps: form A, form B and lactam; (d) IR spectra in heating cell confirm the enantiotropic transition and show the chemical transformation. 


\subsubsection{Isothermal microcalorimetry and solution calorimetry}

\subsubsection{Microcalorimetry}

The decrease in the glass transition temperature, $T_{\mathrm{g}}$, by water and solvents, is the principle behind the microcalorimetric method of amorphous content determination. The substance is subjected to vapours of water, or organic solvent, in an isothermal microcalorimeter (Figure 8.32). The heat flow of crystallisation which is proportional to the amorphous content is measured. The sorption-desorption isotherm presented in Figure 8.33 exemplifies the process. The un-milled sample is not hygroscopic but after micronisation, the powder absorbs water (cycle 2), and an increase in mass is observed. An abrupt decrease is observed in cycle 3 as the drug crystallises and loses water. The corresponding exothermic energy of crystallisation can then be measured.

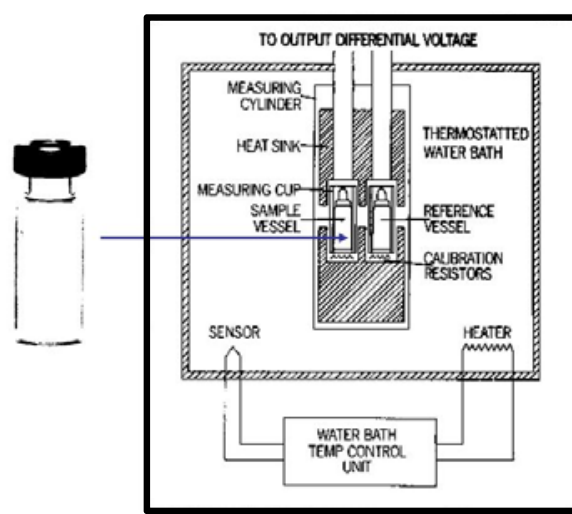

\section{Isothermal Microcalorimetry}

Type:

Thermal Activity Monitor,

Sample volume: $3 \mathrm{ml}$, glass ampoule

Temperature: $\quad 20-80^{\circ} \mathrm{C}$

Precision: $\quad 0.1 \%($ at $300 \mu \mathrm{W})$

Baseline stability: $\pm 0.2 \mu \mathrm{W}(8 \mathrm{~h})$

Humidity control: e.g. $57 \% \mathrm{RH}$

(sat. NaCl-solution)

Figure 8.32. Setting of isothermal calorimeter for quantitation of amorphous content $[17,21]$

a

unmilled b

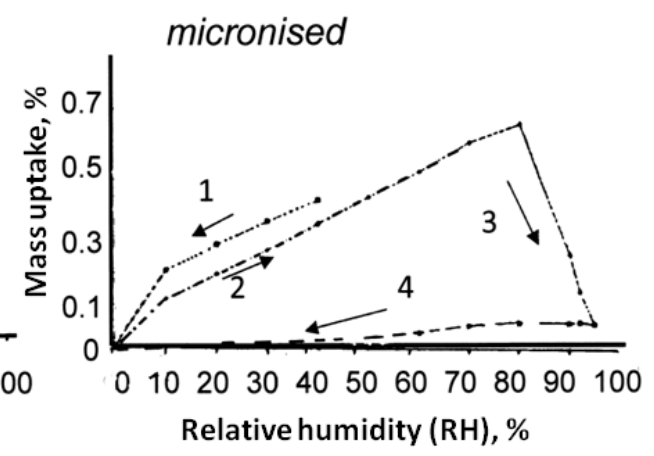

Figure 8.33. Sorption-desorption isotherms (a) before and (b) after micronisation.

Crystallisation of the amorphous part in humid atmosphere

Figure 8.34 shows an example of the determination of amorphous content in a batch of micronised substance for inhalation, by using two different solvent vapours, and the methods were validated. The same result is obtained for this 
batch: $12.9 \%$ compared to $12.7 \%$ amorphous content. However, as demonstrated in Figure 8.34, the time of crystallisation is quite different. With vapours from a mixture of ethanol and water, the crystallisation is rapid, but the start of crystallisation cannot be measured for low amounts of amorphous form. This method can be used in the range $7-15 \%$ of amorphous content. In order to analyse lower contents, dimethylformamide (DMF) used as vapour, can act slowly, and the method has been validated in the range 2 - $30 \%$ amorphous content. An automatic instrument with 48 channels (TA instruments), allows us to perform routine analysis with a limit of detection at the $1 \%$ level.
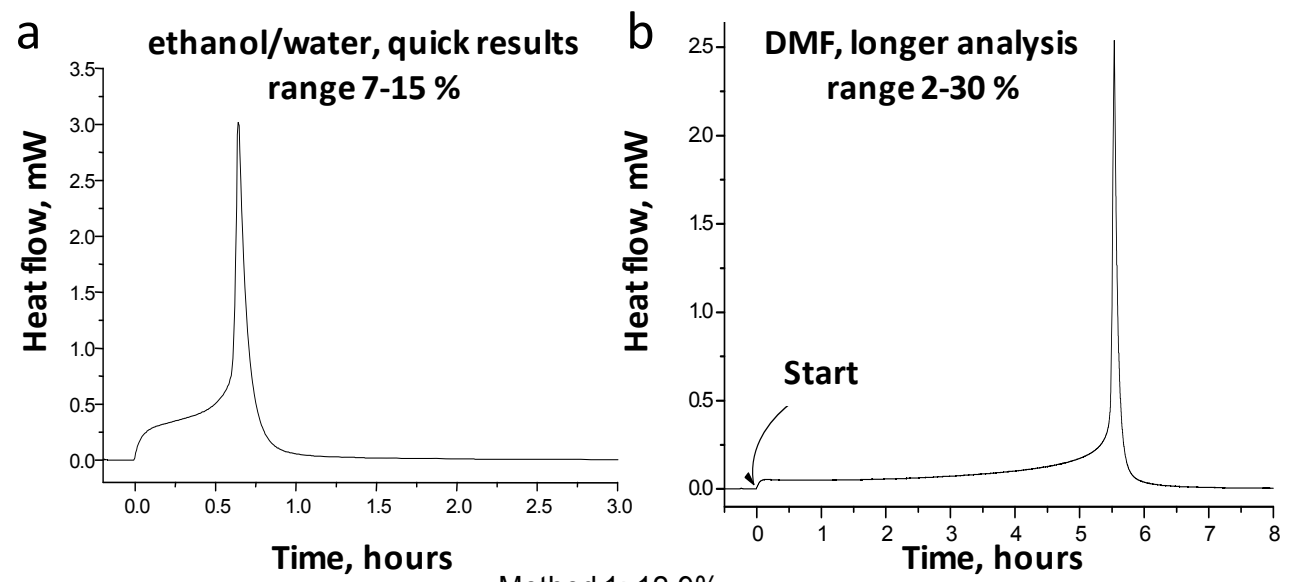

Method 1: $12.9 \%$

Method 2: $12.7 \%$
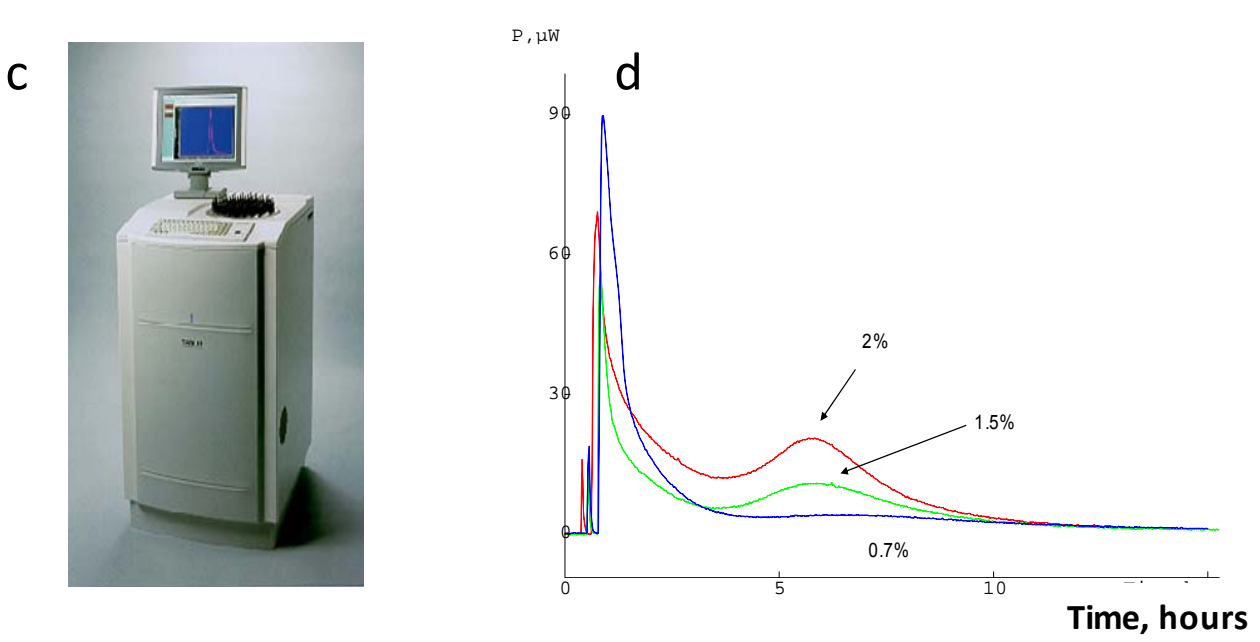

Figure 8.34. Example of quantitative validated methods for the determination of amorphous content by isothermal microcalorimetry; (a) and (b) microcalorimetric curves for a batch with two different methods, (c) automatic isothermal microcalorimetric instrument (TA analysis), (d) comparison of curves with very low amorphous form content 


\subsubsection{Solution calorimetry}

Solution calorimetry has been described in United States Pharmacopeia (USP) for the determination of the amorphous form, but has also been used for quantitation of polymorphs [14]. This method supposes that no other crystalline form may interfere. In the case of enantiotropy:

$$
\Delta H_{\mathrm{t}}=\Delta H_{\mathrm{SA}}-\Delta H_{\mathrm{SB}}
$$

where $\Delta H_{\mathrm{SA}}$ is the heat of solution of form $\mathrm{A}$, and $\Delta H_{\mathrm{SB}}$ the heat of solution of form $\mathrm{B}$. This method can be used for polymorphs, as demonstrated in Figure 8.35 for an enantiotropic drug. The same results for the heat of transition are found by DSC and solution calorimetry $[12,16,18]$. Solution calorimetry is very helpful when the substance decomposes on melting. This approach allows us to choose between forms and select the most stable $[14,18]$.

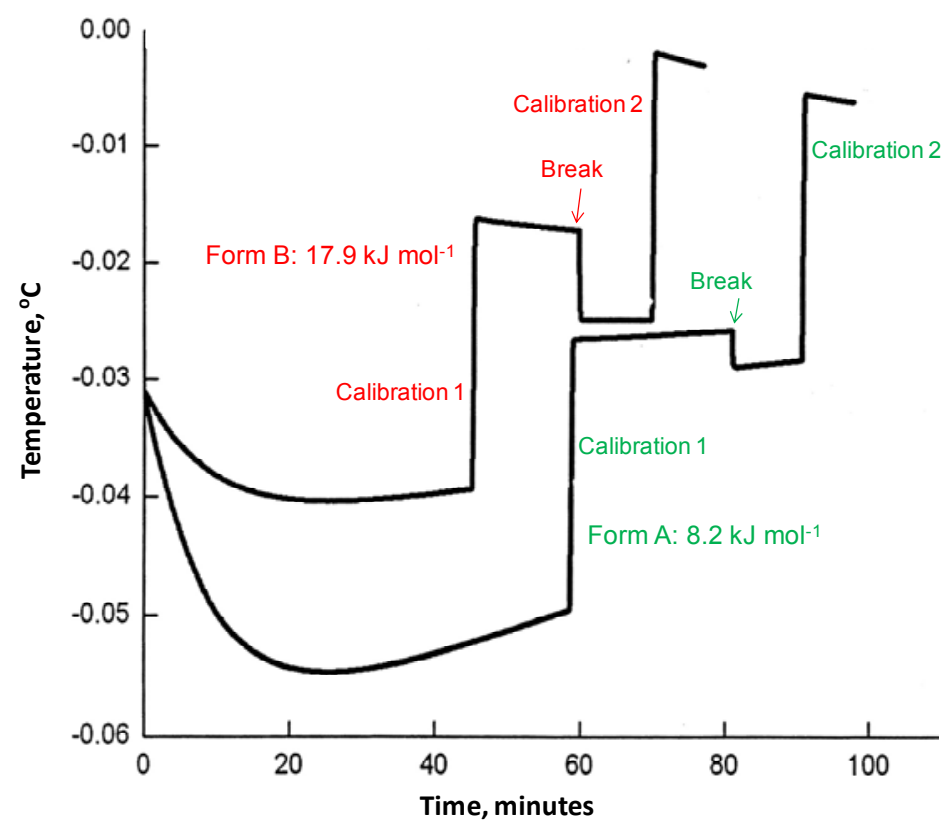

Figure 8.35. Solution calorimetry. Determination of the heat of transition between 2 enantiotrops [16.] Before and after the break of the ampoule containing the substance in water the instrument is calibrated by Joule effect. Heat of transition found by DSC:

$10.4 \mathrm{~kJ} \mathrm{~mol}^{-1}$; Heat of transition found by solution microcalorimetry: $9.7 \mathrm{~kJ} \mathrm{~mol}^{-1}$

\subsection{SOME EXAMPLES OF APPLICATIONS}

\subsubsection{The selection of the right form}

The following example, given in Figure 8.36, is a situation often found in early development. We received a sample, obtained by precipitation, for which the DSC scan exhibits dual melting. By using different heating rates it was possible to 
calculate the melting enthalpies and it was concluded that the sample is an enantiotropic system. The polymorphism study of slurries in different solvents of a purer sample gave a third form. According to Burger's rule, and the equilibration study, $\mathrm{C}$ is the stable form, $\mathrm{A}$ and $\mathrm{B}$ are enantiotrops, and both are monotrops to C. Consequently, form $C$ was selected for further study [32].

In solid state $A \Leftrightarrow B$ but $A$ and $B$ monotrops to $C$

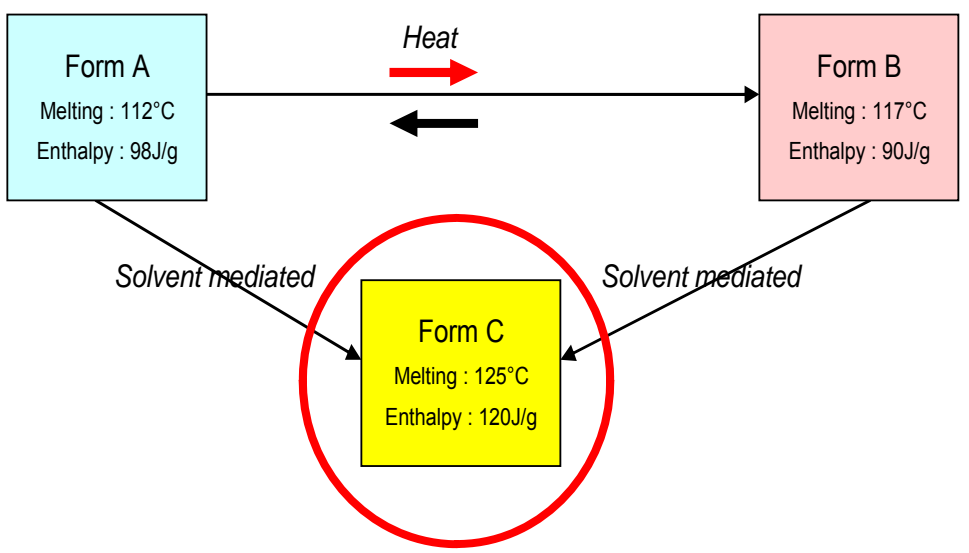

Figure 8.36. Case of a drug candidate with two enantiotropic metastable forms obtained in research laboratory. A third form was thermodynamically stable [32]. Summary of their relationships.

\subsubsection{Sensitivity of DSC}

Figure 8.37 deals with a drug substance for which traces of a stable form (form B) acted as a catalyst for quick transformation if the samples were not kept at very low temperatures. DSC proved more sensitive and allowed monitoring $[15,18]$.

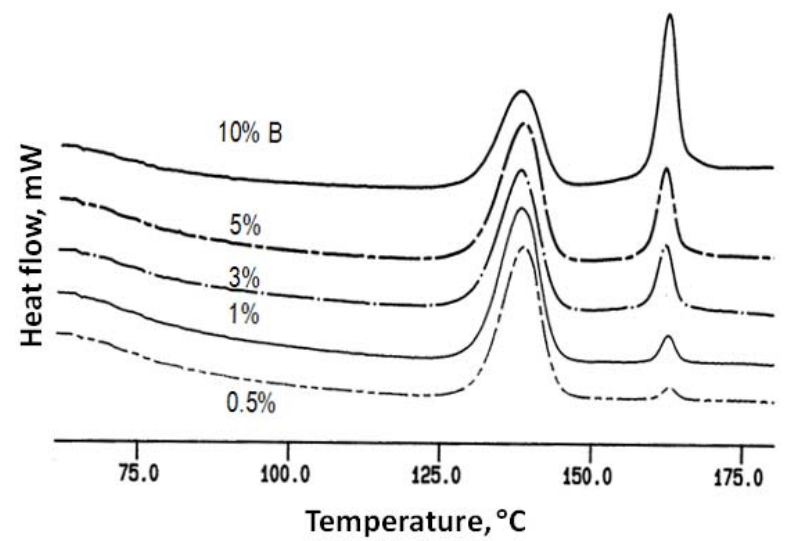

Figure 8.37. Example of quantitative determination of undesirable form by the melting DSC curve. Sensitivity of DSC: traces of a stable form acting as seeds by aging are determinable $[15,17]$ 


\subsubsection{Disappearing solvates}

Solvates are very often formed in the presence of volatile solvents. By isolation in the air they easily transform into anhydrous forms, stable or unstable, in amorphous powder, or in hydrated forms. The best way to detect them would be direct measurement in the crystallisation vessel. Figure 8.38 shows the results of a large number of experiments to understand the complex situation found with a drug substance.

\section{Crystallisation in ethanol $<40^{\circ} \mathrm{C}$ form $\mathrm{A},>50^{\circ} \mathrm{C}$ form $\mathrm{B}$ Which form to be selected?}

Burger's rule? A: one DSC peak B: two DSC peaks with decomposition $X$-ray heating cell: $B \Rightarrow A$ before melting and decomposition

Slurry experiments form A, form B and mixture $A+B$ at $10,25,40$, 50 and $60^{\circ} \mathrm{C}$ at different times and solvents. Analysis of solids
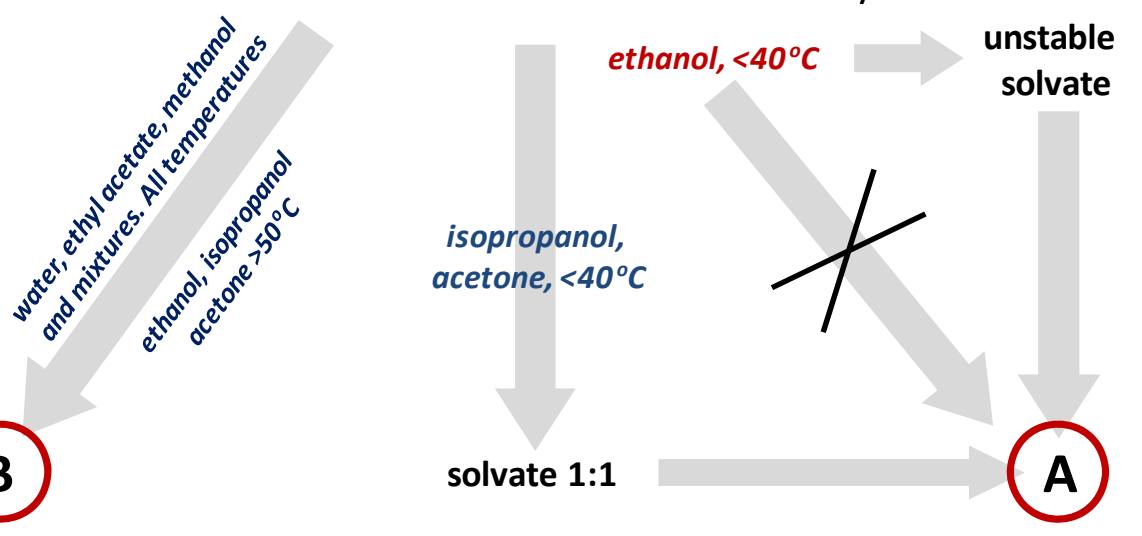

Figure 8.38. Disappearing solvates. Example of experiments conducted to select the right form [18]

\subsubsection{Selection of the best form considering the pharmaceutical environment}

Water is present in the air and in excipients, and is often used in mixtures for crystallisation purposes. The TG curves of hydrates can be considered fingerprints. Figure 8.39 is an example of the coexistence of monohydrate and trihydrate in the solvent mixture of a process. The TG curve permitted the evaluation of the presence of the trihydrate, since trihydrate and monohydrate had separated steps for the loss of water $[16,18]$. Figure 8.40 is an example of the relationships needed to select thermodynamic windows for hydrates [12]. 
a

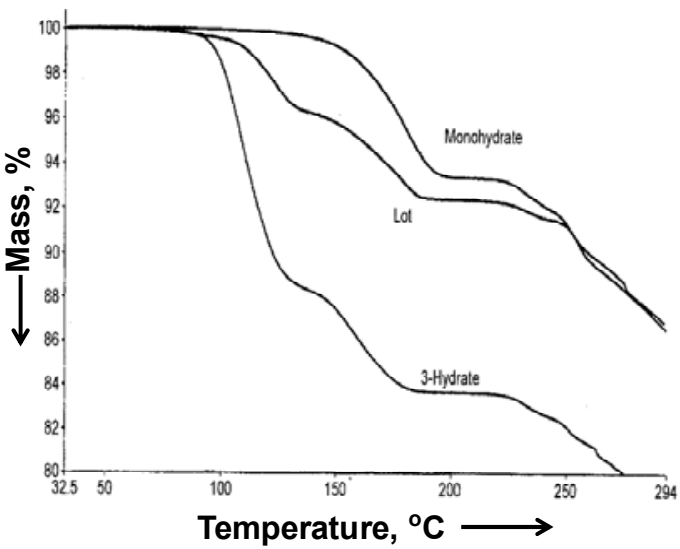

b

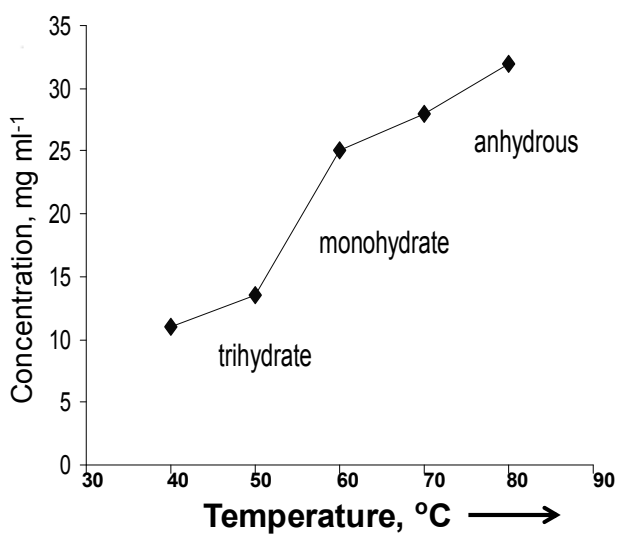

Figure 8.39. Detection of impure hydrates by TG.

(a) TG curves of the monohydrate, the trihydrate and of an impure sample containing both;

(b) solubility behaviour of the monohydrate and of the trihydrate [18]

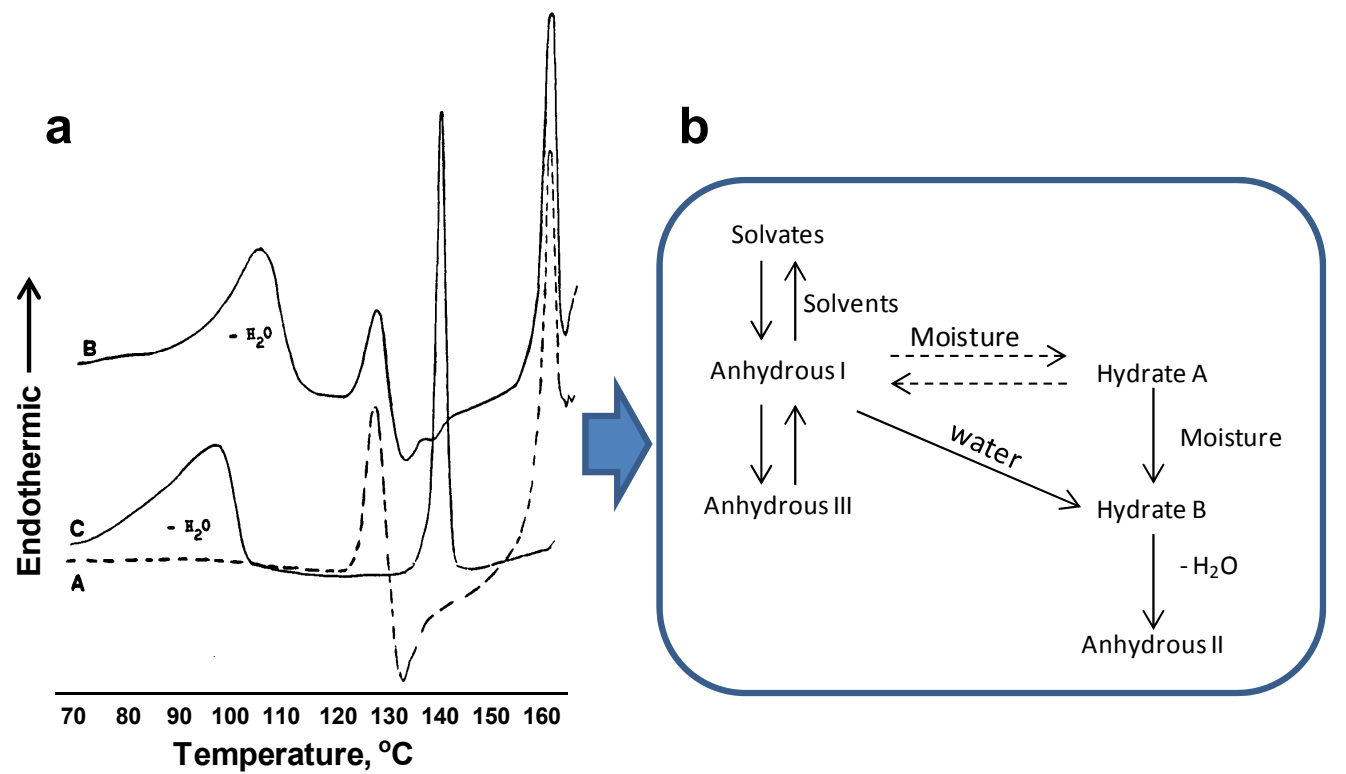

Figure 8.40. Example of relationships in a complex problem of hydrates and solvates.

(a) As demonstrated on the DSC curves the dehydration of two polymorphs of the hydrate occur differently.

A: DSC of anhydrous form I with transformation into anhydrous III.

B: polymorphic hydrate A looses water and gives the anhydrous form I.

C: polymorphic hydrate B looses water into the anhydrous form II;

(b) A scheme of the relationships between solvates, hydrates and anhydrous form 


\subsection{CONCLUSION}

In conclusion, thermal analysis and calorimetric techniques are necessary for the selection and the characterisation of solid forms. They are versatile and offer quick results. As exemplified in Figure 8.41, characterisation of the relationship between all forms is the objective of development. For this challenging purpose a range of methods is necessary, and when this is achieved, process analytical technology will be the future for upscale and manufacture.

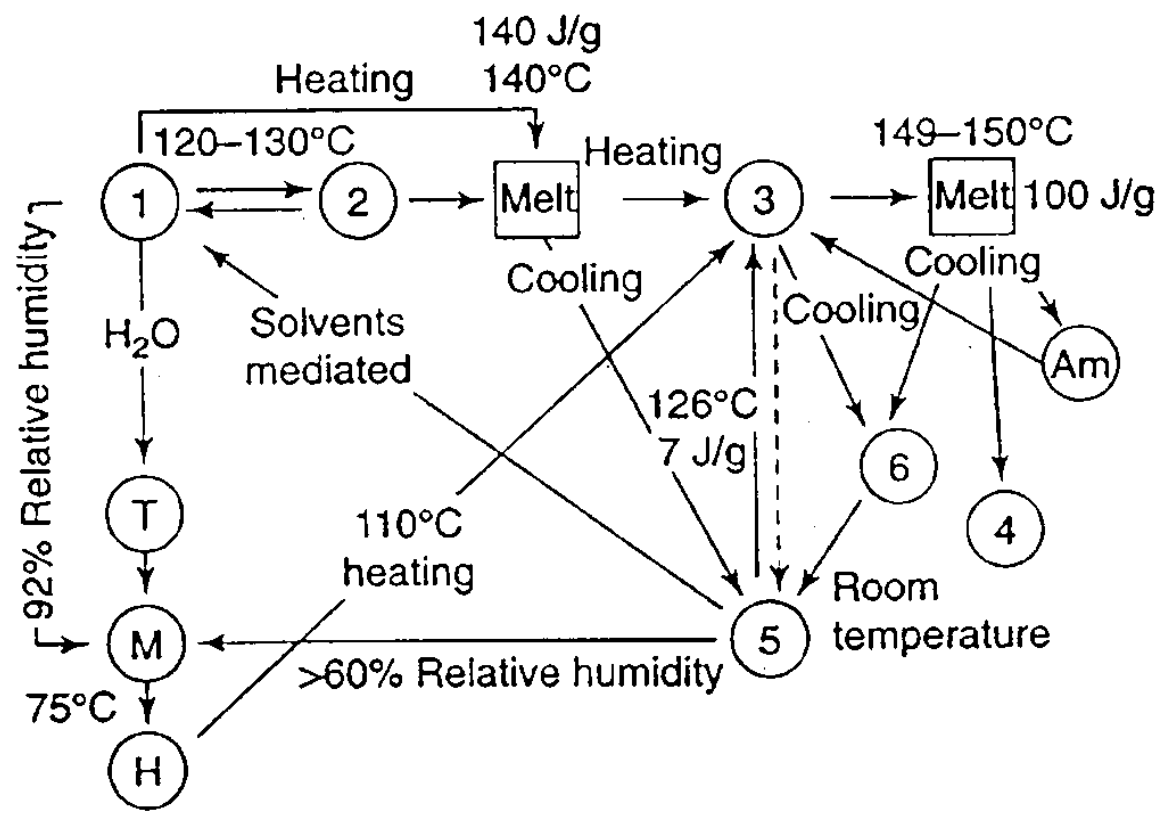

Figure 8.41. Relationships between the solid phases of tetracaine hydrochloride according to [41]. For the study, DSC, TG and temperature resolved XRD as well as solubility and slurries experiments were performed. 6 cristalline anhydrous forms were identified, an amorphous form, a tetrahydrate, a monohydrate and a hemi-hydrate. At room temperature only anhydrous forms 1 and 5 could be obtained for a long period of time. Form 1 is the stable form and corresponds to the commercial quality

\section{REFERENCES}

1. Guideline Specification Q6A. Investigating the need to set acceptance criteria for polymorphism in drug substances and drug products. International Conference on Harmonization (ICH) (1999).

2. L. Le Chatelier. Compte Rendu. 104 (1886) 1243.

3. G. Höhne, W. Hemminger, H.J. Flammersheim. Handbook of Thermal Analysis and Calorimetry. Springer, 2003.

4. P.J. Haines. Principles of Thermal Analysis and Calorimetry. RCS Paperback, 2002.

5. P. Gabbott. Principles and Applications of Thermal Analysis. Wiley-Blackwell Publ. (2007). 
6. D.Q.M. Craig, M. Reading. Thermal Analysis of Pharmaceuticals. CRC Press, UK 2006.

7. W-P. Pan, L. Judovits. Techniques in thermal Analysis, hyphenated techniques, Thermal Analysis of surface, fast rate analysis. ASTM, 2007.

8. D. Giron, Thermal Analysis of Drugs and Drug Products. In: Encyclopedia of Pharmaceutical Technology. (Eds. J. Swarbrick, J.C. Boylan) Marcel Dekker, 2006.

9. D. Giron. Thermal Analysis and microcalorimetric methods in the industry: essential techniques for proper development of pharmaceuticals. European Pharmaceutical Review 2006 (5) 84-90.

10. D.Giron. Latest Development in the area of thermal analysis and calorimetry that are impacting on pharmaceutical manufacturing. European Pharmaceutical Review 2008 (2) 71-76.

11. B. Rodriguez-Spong, C.P. Price, A. Jayasankar, A.J. Matzger, N. Rodriguez-Hornedo. General principles of pharmaceutical solid polymorphism: A supramolecular perspective. Advanced Drug Delivery Reviews 56(3) (2004) 241-274.

12. D. Giron. Thermal analysis and calorimetric methods in the characterization of polymorphs and solvates. Thermochimica Acta 248 (1995) 1-59.

13. D. Giron. Le polymorphisme. Labo-Pharma Problèmes et techniques. 307 (1981) 151-160.

14. D. Giron. Investigations of polymorphism and pseudo-polymorphism in pharmaceuticals by combined thermoanalytical techniques. Journal of Thermal Analysis and Calorimetry 64(1) (2001) 37-60.

15. D. Giron. Monitoring of polymorphism from detection to quantification. Engineering in Life Sciences 3(3) (2003) 103-112.

16. D. Giron, M. Mutz, S. Garnier. Solid-state of pharmaceutical compounds: Impact of the ICH Q6 guideline on industrial development. Journal of Thermal Analysis and Calorimetry 77(2) (2004) 709-747.

17. D. Giron, S. Monnier, M. Mutz, T. Buser, F. Stowasser, K. Schulze, M. Bellus. Comparison of quantitative methods for analysis of polyphasic pharmaceuticals. Journal of Thermal Analysis and Calorimetry 89(3) (2007) 729-743.

18. D. Giron, S. Monnier, M. Mutz. Challenging characterization and monitoring of polymorphs. Latest developments. Lecture presented at AFCAT-GEFTA-STK meeting, Mulhouse, 2008.

19. I.M. Vitez. Utilization of DSC for pharmaceutical crystal form quantitation. Journal of Thermal Analysis and Calorimetry 78(1) (2004) 33-45.

20. S. Gaisford, M. A.A. O’Neil, Pharmaceutical Isothermal Calorimery, Informa Healthcare, 2007.

21. M. Mutz, A. Motreff, M. Monnier, T. Buser, P. Schwab, D. Giron. Use of high throughput microcalorimeter for faster determination of amorphous content. STK annual meeting, June 2006, Fribourg, Switzerland.

22. G. Buckton, P.Darcy, A.J. Mackellar. The use of isothermal microcalorimetry in the study of small degrees of amorphous content of powders. International Journal of Pharmaceutics 117(2) (1995) 253-256.

23. D. Giron, P. Remy, S.Thomas, E. Vilette. Quantitation of amorphicity by microcalorimetry. Journal of Thermal Analysis and Calorimetry 48(3) (1997) 465-470.

24. B.Shah, V.K. Kakumanu, A.K. Bansal. Analytical techniques for quantification of amorphous/crystalline phases in pharmaceutical solids. Journal of Pharmaceutical Science 95(8) (2006) 1641-1665. 
25. M. Savolainen, K. Jouppila, O. Pajamo, L. Christiansen, C. Strachan, M. Karjalainen, J. Rantanen. Determination of amorphous content in the pharmaceutical process environment. Journal of Pharmacy and Pharmacology 59(2) (2007) 161-170.

26. S.R. Chemburkar, J.B.K. Deming, H. Spiwek, K. Patel, J. Morris, R. Henry, S. Spanton, W. Dziki, W. Porter, J. Quick, P. Bauer, J. Donaubauer, B.A. Narayanan, M. Soldani, D. Riley, K. McFarland. Dealing with the impact of ritonavir polymorphs on the late stages of bulk drug process development. Organic Process Research and Development 4(5) (2000) 413-417.

27. A.Burger, R. Ramberger. On the polymorphism of pharmaceuticals and other molecular crystals. Theory of thermodynamic rules. Mikrochimica Acta [Wien] II 72(3) (1979) 259-271.

28. Burger, U.J. Griesser. Scientia Pharmaceutica. 58 (1990) 423-430.

29. M. Soustelle. In: Handbook of powder technology, Vol.9. Powder Technology and Pharmaceutical Processes (Eds. D. Chulia, M. Deleuil, Y. Pourcelot) Elsevier 1994.

30. B.C. Hancock, G. Zografi. Characteristics and significance of the amorphous state in pharmaceutical systems. Journal of Pharmaceutical Science 86(1) (1997) 1-12.

31. D. Giron, C. Goldbronn. Place of DSC purity analysis in pharmaceutical development. Journal of Thermal Analysis and Calorimetry 44(1) (1995) 217-251.

32. D. Giron. Polymorphism: Thermodynamic and kinetic factors to be considered in chemical development. American Pharmaceutical Review 8 (2005) 32-37 and 7279.

33. D. Giron. Characterisation of salts of drug substances. Journal of Thermal Analysis and Calorimetry 73(2) (2003) 441-450.

34. D. Giron, C. Golbronn, M. Mutz, S. Pfeffer, P. Piechon, P. Schwab. Solid state characterization of pharmaceutical hydrates. Journal of Thermal Analysis and Calorimetry 68(2) (2002) 453-465.

35. W.Chongcharoen, S.R. Byrn, N. Sutanthavinu. Solid state interconversion of norfloxacin hydrates. Journal of Pharmaceutical Science 97(1) (2008) 473-487.

36. A.K. Salameh, L.S. Taylor. Physical stability of crystal hydrates and their anhydrates in the presence of excipients. Journal of Pharmaceutical Science 95(2) (2006) 446-461.

37. M. Ollivon, G. Keller, C. Bourgaux, D. Kalnin, P. Villeneuve, P. Lesieur. Journal of Thermal Analysis and Calorimetry 85(1) (2006) 219-224.

38. Kichi, H. Toraya. Simultaneous measurements of X-ray diffraction (XRD) and differential scanning calorimetry data under controlled humidity conditions: instrumentation, and application to studies on hydration, dehydration and re-hydration process of pharmaceutical compounds. Advances in X-ray Analysis 47 240-248.

39. Rodriguez, D.E. Bugay. Characterization of pharmaceutical solvates by combined gravimetric and infrared analysis. Journal of Pharmaceutical Science 86(2) (1997) 263-266.

40. F. Eigenmann, M. Maciejewski, A. Baiker. Quantitative calibration of spectroscopic signals in combined TG-FT-IR systems. Thermochimica Acta 440(1) (2006) 81-92.

41. D. Giron, M. Draghi, C. Goldbronn, S. Pfeffer, P. Piechon. Study of polymorphism of tetracaine hydrochloride. Journal of Thermal Analysis and Calorimetry 49(2) (1997) 913-927. 